\title{
Memory Retrieval in Mice and Men
}

\author{
Aya Ben-Yakov ${ }^{1}$, Yadin Dudai ${ }^{1,2}$, and Mark R. Mayford ${ }^{3}$ \\ ${ }^{1}$ Department of Neurobiology, Weizmann Institute of Science, Rehovot 76100, Israel \\ ${ }^{2}$ Center for Neural Science, New York University, New York, New York 10003 \\ ${ }^{3}$ Department of Molecular and Cellular Neuroscience, The Scripps Research Institute, La Jolla, California 92037 \\ Correspondence: yadin.dudai@weizmann.ac.il; mmayford@scripps.edu
}

Retrieval, the use of learned information, was until recently mostly terra incognita in the neurobiology of memory, owing to shortage of research methods with the spatiotemporal resolution required to identify and dissect fast reactivation or reconstruction of complex memories in the mammalian brain. The development of novel paradigms, model systems, and new tools in molecular genetics, electrophysiology, optogenetics, in situ microscopy, and functional imaging, have contributed markedly in recent years to our ability to investigate brain mechanisms of retrieval. We review selected developments in the study of explicit retrieval in the rodent and human brain. The picture that emerges is that retrieval involves coordinated fast interplay of sparse and distributed corticohippocampal and neocortical networks that may permit permutational binding of representational elements to yield specific representations. These representations are driven largely by the activity patterns shaped during encoding, but are malleable, subject to the influence of time and interaction of the existing memory with novel information.

$\mathrm{R}_{\mathrm{i}}^{\mathrm{e}}$ etrieval is the use of learned information, induced by sensory or internal cues. In simple modified reflex behavior, it refers to the postexperience readout of the experience-induced change in behavior and in its underlying synaptic efficacy (Kandel and Schwartz 1982; Byren and Hawkins 2015). In memories encoded and stored in more complex circuits, such as distributed memories in the mammalian brain, retrieval is posited to involve distinct processes, including selection, reactivation or reconstruction of the target representation, and assessment of the outcome (Tulving 1983; Dudai 2002). These sequential and parallel processes can be completed within a fraction of a second (e.g., Thorpe et al. 1996). Retrieval is critical to understanding memory. In fact, once encoding is over, memory unretrieved, whether naturally or by experimental manipulations, is undetected, hence retrieval of the engram or part of it is an essential part of the proof that the specific engram exists.

Despite its central importance in the study of memory and the abundance of data and models of retrieval in human experimental psychology, until fairly recently, retrieval in complex neural circuitry remained mostly an uncharted terrain in the neuroscience of memory. This was owing to a multitude of hindrances, including difficulties in teasing apart retrieval from encoding, limited knowledge on localization of specific candidate memory circuits in humans and animals, and lack of neurobiological methods with the proper spatiotemporal

Editors: Eric R. Kandel, Yadin Dudai, and Mark R. Mayford

Additional Perspectives on Learning and Memory available at www.cshperspectives.org

Copyright (C) 2015 Cold Spring Harbor Laboratory Press; all rights reserved; doi: 10.1101/cshperspect.a021790

Cite this article as Cold Spring Harb Perspect Biol 2015;7:a021790 
A. Ben-Yakov et al.

resolution that permits monitoring and manipulation of these circuits to observe, block, trigger or enhance retrieval. The development of novel paradigms, model systems, and new tools in molecular genetics, electrophysiology, optogenetics, in situ microscopy and functional imaging, have contributed markedly in recent years to our ability to investigate retrieval and understand part of its processes and mechanisms from the cellular to the behavioral level. In this work, we will review some of these developments. We will begin with selected studies of memory retrieval in the rodent brain and proceed to discuss aspects of retrieval of episodic memory in the human brain.

\section{MEMORY RETRIEVAL IN THE RODENT BRAIN}

The study of memory retrieval in the mammalian brain assumes that the process involves reactivation of patterns of neural activity associated with the original experience, although not necessarily identical with the activity patterns that represented the original experience. Retrieval is hence considered as a reconstructive rather than a replicative process. This activity is likely to be sparse and anatomically distributed, with different brain regions contributing to the quality and strength of the recall. Although the human work focuses on a richer psychology and more complex neuroanatomy than accessible in the rodent, a common theme in both strands of research is a search for coherent patterns of activation correlated with retrieval and for correlations between retrieval and initial learning. The rodent work has been spurred recently by techniques that allow direct activation of distributed neural ensembles to test their functional involvement in memory. We will focus first on the role of hippocampal and cortical circuits in the retrieval of explicit memories in the mouse and rat.

\section{Patterned Activity during Retrieval}

As discussed in the literature, the hippocampus plays a critical role in explicit forms of memory that in rodents has been investigated extensively in relation to spatial learning (Morris et al.
1982). A striking feature of the rodent hippocampus is the identification of place cells (O'Keefe and Dostrovsky 1971), neurons that fire when the animals enter specific locations in their environment (Moser et al. 2015). This has led to the view that the hippocampus forms a cognitive map; it encodes a map of space that can be used to allow recognition of specific environments, guide movement through the environment, and identify specific goal areas within an environment (O’Keefe 1990). At a circuit level, the hippocampus (and surrounding structures such as entorhinal and perirhinal cortex) could serve this function by integrating multimodal sensory information to form a unique map of each particular environment, object, or event. During retrieval, when a sufficient partial set of cues is provided, the entire map (memory) is recruited in a manner that likely involves the activation of multiple cortical regions coordinated by the hippocampus. A first question we can ask is how similar is the pattern of neural activity during two retrieval trials, or during retrieval and initial learning?

One means of assessing neural activity is through examination of a group of genes, the immediate early genes (IEGs), whose expression in neurons is responsive to activity (Farivar et al. 2004). The most commonly used IEGs for neural activity mapping are $c f o s$, arc, and zif268. The expression of these genes is modulated by a variety of second messenger signaling pathways, but in excitatory neurons these all seem to be linked to neural activity (Morgan et al. 1987; Sagar et al. 1988). The $c f o s$ gene has been used most extensively in the analysis of rodent behavior and is responsive to burst activity of 30 or more action potentials at frequencies of $10 \mathrm{~Hz}$ or above (Schoenenberger et al. 2009). It has been used in many behavioral studies examining different brain areas and generally indicates activity in areas consistent with the known electrophysiological responses to the behavior. Although the use of IEG expression offers a simple assay for neural activity with cellular resolution, it lacks temporal resolution, the ability to assess low levels of activity - for example, single action potentials, and the ability to determine activity patterns at more than one time point, which is 
a requirement for determining the stability of neural ensemble activity during learning and retrieval or across multiple retrieval trials.

The problem of determining activity patterns at two different time points with IEGs was addressed with a method called compartmental fluorescent in situ hybridization (catFISH) (Guzowski et al. 1999). This approach takes advantage of the fact that genes that are being actively transcribed will have unspliced mRNA in the nucleus but relatively little processed transcript in the cytoplasm at short time points after induction. Cells that were active in the past, but are currently silent, will have mRNA in the cytoplasm but no nuclear transcript. The approach was used with the arc gene to test ensemble activity in the hippocampus in animals that explore an identical environment twice (A-A) compared with animals exploring two distinct environments (A-B). The study found greater ensemble reactivation in CA1 neurons (40\%) when the two environments explored were identical (A-A group) versus when they were distinct (A-B group, 15\% reactivation). This result is consistent with the idea that the hippocampus is encoding a representation of place that is reactivated when the information is retrieved. However, there are a number of caveats to this interpretation. First, the experiment is really just comparing the activity pattern of two sensory experiences rather than retrieval of a memory. Second, the technique only allows the comparison of ensemble activity at two closely spaced time points (30 min or less) and so does not indicate the stability of these ensembles over long time frames or in multiple retrieval trials. Finally, the link of IEGs to neural activity is crude and does not allow precise assessment of activity patterns or low levels of activity as can be achieved with electrophysiological recording.

Classical hippocampal recording techniques cannot readily detect large ensembles of neurons stably over long periods of time, making it difficult to use for the type of experiment discussed above. An alternative approach is the use of genetically encoded reporters of calcium levels combined with optical imaging of the transient fluorescent signals produced on calci- um binding (Akerboom et al. 2012). This approach offers a level of temporal resolution and action potential sensitivity that is intermediate between physiological recording and IEG expression, with the advantage that the neurons are precisely identified anatomically and can be stably imaged over long time periods. This approach was used to simultaneously record the activity of between 500 and 1000 CA1 hippocampal neurons over 45 days while the animals ran on a linear track in a constant spatial environment (Ziv et al. 2013). As seen in previous electrophysiological studies, on any given day, the neurons showed clear spatial firing fields with $\sim 20 \%$ of neurons meeting the criteria for place cells. However, between any 2 days, the precise ensemble of neurons recruited in each session showed a lower level of stability. At 5 days separation between recording sessions, there was a $25 \%$ overlap in the identity of place cells recorded in the two sessions. The overlap dropped to $15 \%$ at 30 days separation between recording sessions with only $\sim 3 \%$ of cells active in all 10 recording sessions. So while on each day $20 \%$ of the CA1 neurons were active as place cells on the track, the majority of those cells were different from day to day in identical spatial environments. If the hippocampus is representing the environment through the activity of place cells, then why is there not greater stability of the ensemble of neurons activated when the animal is reexposed to that environment?

There are several possible explanations for the apparent instability in hippocampal ensembles in the preceding experiment. One possibility is that there are subtle differences in the environment from day to day to which the animal is responding. Another possibility is that the task (running for a water reward) was not sufficiently salient to produce a stable representation. A previous study in mice using tetrode recordings showed that the stability of place cells over several days is modulated by the salience of the task the animals were required to perform in that environment (Kentros et al. 2004). Having non-food-deprived animals collect food pellets during the recording caused the place cells to be unstable from day to day while requiring the animals to attend by demanding that they nav- 
igate to a specific location to avoid an aversive light/noise cue produced the greatest temporal stability in place cell firing. Another possibility is that the CA1 neurons are encoding a component of time such that each successive day the ensemble varies to indicate that, although the environmental cues are identical, today's exploration is a different event in time from the previous days. This was suggested by electrophysiological recording of place cells over hours to days where it was found that many CA1 neurons changed their firing rate over time, consistent with the calcium imaging studies above, although the CA3 neurons showed greater session-independent stability in firing pattern (Mankin et al. 2012). Thus, the CA3 region of the hippocampus may hold an environment-specific map with the CA1 region adding information related to the specific time the environment is explored. Finally, it is possible that the critical spatial signal is contained in the small percentage of neurons that do show consistent firing between multiple recording sessions or in subtleties in the activity patterns that are below the threshold of this technique to resolve.

Whatever the explanation, this experiment raises an important question in understanding how memories are represented and retrieved. How consistent is the pattern of brain activity in response to two identical sensory inputs or two memory recall events? What is noise and what is signal in the pattern of neural activity that is observed? Certainly the brain's ability to consistently recognize and learn about elements in the environment implies some coherent signal in the neural activity patterns induced by the same sensory stimulation, but the models and approaches to understanding this information will differ depending on whether the signal is a dominant or a minor component of the sensory-evoked activity.

The examination of activity patterns during learning and retrieval or during two bouts of memory retrieval provide one means of identifying a neural signal associated with memory recall. As we have seen above, these experiments provide somewhat conflicting data regarding the degree of ensemble reactivation fidelity during different retrieval events. These experiments are also conceptually problematic in that they do not truly differentiate memory retrieval from sensory processing or encoding. When animals are placed in the same environment twice, they experience the same sensory cues and any consistency in the neural ensemble activity could reflect the processing of these cues rather than memory retrieval. Finally, even if the neural activity represents memory retrieval, the data are correlative and would require direct manipulation to test for functional relevance.

\section{Optogenetic Manipulation during Retrieval}

One approach to directly test the function of distributed ensembles of active neurons in the mouse has recently been developed (Reijmers et al. 2007). The approach uses a transgenic mouse that allows the genetic modification of neurons based on their natural, environmentally evoked, activity patterns within an experimentally controlled time window. The IEGs, discussed above, are genes that are expressed in response to neural activity and previous studies have shown that their DNA promoter elements could confer this activity-dependent expression on linked reporters in transgenic mice (Smeyne et al. 1992). This was exploited to develop a binary genetic system in which neural activity at a given point in time could drive expression of any gene of interest (GOI) in the active neurons (Fig. 1). In this system, the cfos promoter is used to drive expression of the tetracycline transactivator (tTA), a transcription factor that can be modulated by the antibiotic doxycycline (Dox), a derivative of tetracycline. The tTA can activate the expression of a second gene when it is linked to a tetracycline-responsive promoter element (TRE). In animals carrying two transgenes, cfos-tTA and TRE-GOI, the expression of tTA is directly linked to natural neural activity by the cfos promoter rising and falling as neurons become active. In the presence of Dox the transcriptional activity of the tTA is blocked, preventing downstream activation from the GOI. When Dox is removed, the GOI will now be expressed (via tTA driven transcription) in all neurons that are sufficiently active to drive the cfos-linked tTA. This allows the genetic modi- 
A

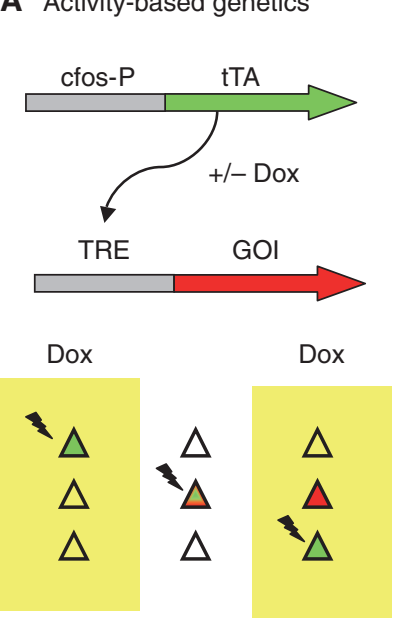

B

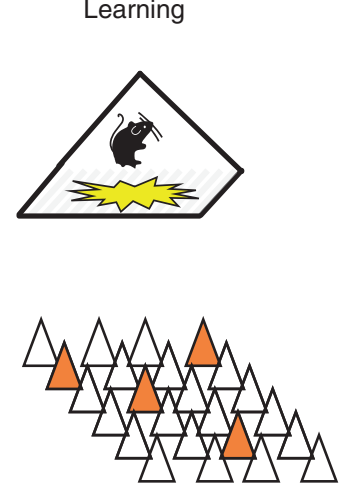

$\bigwedge$ ChR2 expression
Artificial retrieval

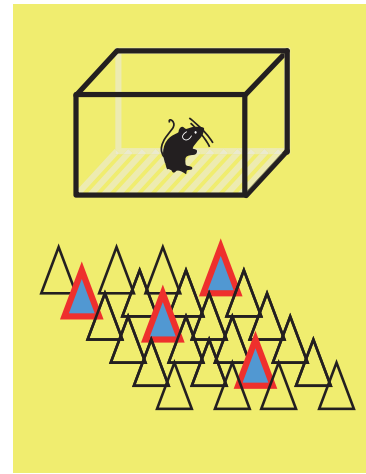

Light activated

Figure 1. Memory retrieval induced by direct circuit reactivation. (A) System for introducing genes into neurons based on their natural, sensory-evoked activity patterns (Reijmers et al. 2007). The cfos-promoter drives tetracycline transactivator (tTA) in response to neural activity and the tTA then activates and gene of interest (GOI) that is linked to a TRE-promoter. Doxycycline (Dox-yellow shading) blocks the transcriptional activity of tTA providing temporal control over the time frame in which neural activity drives the GOI. $(B)$ Experimental design for demonstrating the functional relevance of distributed neural ensembles. Neurons activated during learning in a fear-conditioning paradigm are genetically tagged with channelrhodopsin (ChR2). The subsequent light-induced firing of these ensembles is able to produce a fear response in a second, emotionally neutral, context.

fication of neurons active at specific points in time in response to specific environmental stimuli, for example, learning or retrieval cues.

The approach was used in several recent publications to test the psychological relevance of distributed neural ensembles activated during learning in a contextual fear-conditioning task (see Fanselow and Wassum 2015). In contextual fear conditioning, animals receive footshocks in a particular context (the conditioning box) that contains multimodal sensory cues (generally distinct visual, tactile, and odor cues). Memory retrieval is assessed by the fear response the animals display when returned to the conditioning chamber. This is a model of explicit memory that is sensitive to hippocampal lesions and, reported by a number of groups, to show the temporal gradient in amnesia seen in many studies of human hippocampal patients with older (consolidated) context memories insensitive to hippocampal lesion (Kim and Fanselow 1992; Anagnostaras et al. 1999; Squire and Bayley 2007). In Liu et al. (2012), cfos-based genetic tagging was used to introduce channelrhodopsin (ChR2) into dentate gyrus (DG) neurons that were activated during contextual fear learning. Mice were placed in one of two contexts A or $\mathrm{B}$ (conditioning boxes with different visual, tactile, and odor cues) and the neurons that were naturally activated by this environmental exploration were tagged with ChR2 to allow their subsequent direct activation with light. Both groups of mice were then fear conditioned to context A while on Dox, to prevent any further labeling of active ensembles. When mice in which DG neurons were tagged in context A were also fear conditioned in context $\mathrm{A}$, the subsequent stimulation of the ChR2 expressing neurons produced a fear response in a neutral environment. Stimulation of those neurons that were genetically tagged with ChR2 while animals explored context $\mathrm{B}$ failed to produce fear in animals conditioned to fear context A. This suggests that the ensemble of neurons activated during the exploration of context $A$ is capable of producing memory retrieval when directly stim- 
ulated. That is, the brain represents the conditioning box through the activity of the ensemble of neurons active in the DG during initial exploration (learning) and presumably through downstream neurons in other brain regions that are activated when this ensemble is directly stimulated via ChR2.

It is quite remarkable that the highly nonphysiological stimulation that is produced with ChR2, which fires all neurons simultaneously and thus eliminates any temporal sequence effects or coordination with endogenous rhythms, can apparently produce a coherent internal representation of a complex environment. To further explore this idea, a complementary experiment was performed to determine whether the ensemble activity in the DG could serve as a conditioned stimulus (CS) in fear conditioning. In this case, cfos-activated neurons were genetically tagged with ChR2 while the animals explored context A, as in the previous study. However, now the ChR2 labeled ensemble was activated in a neutral context and paired with footshocks. Thus, the artificial stimulation served as a CS that was paired with a footshock unconditioned stimulus (US). In this case, the animals developed a fear response to context A even though they never actually received the aversive shock US in that environment (Ramirez et al. 2013). Taken together, these results provide support for the notion that the activity of DG neural ensembles is sufficient to represent the context and serve as a cue for memory encoding and retrieval.

The artificial stimulation of small ensembles of neurons in the DG region of the hippocampus allows the retrieval of contextual memories presumably by activating more distributed ensembles of neurons in downstream hippocampal and cortical regions. Given the highly parallel nature of neural connectivity and processing, it is possible that although these ensembles may be sufficient for retrieval, they are not necessary as other pathways could compensate. The question of necessity was addressed in two recent studies using a light-gated proton pump from archaebacteria (ArchT) to hyperpolarize and silence cfos tagged neural ensembles in experiments analogous to those described above with
ChR2 (Denny et al. 2014; Tanaka et al. 2014). Both teams of investigators also used context fear conditioning and examined the requirement for ensembles in three different hippocampal regions, the DG, CA3, and CA1. Expression of ArchT was driven into neurons that were active during learning in context fear conditioning, and these ensembles were subsequently silenced in either the DG, CA3, or CA1 during memory retrieval. In each case, the silencing impaired the retrieval of the contextual fear memory. These results show that in each of the three major hippocampal subregions, the reactivation of the ensemble of neurons active during initial learning is necessary for the subsequent retrieval of the memory. This is consistent with the view that retrieval involves the reconstruction of patterns of brain activity produced during initial learning.

\section{Retrieval of Consolidated Memories}

Another notable aspect of memory and its retrieval is the change in circuit structure of hippocampal-dependent memories over time, originally exemplified in amnesic patients such as H.M. (Squire and Dede 2015). The observation that newly formed memories require the hippocampus for retrieval, but following weeks (in rodents) or months to years (in humans), the hippocampus seems to become dispensable for at least some forms of explicit memory, suggests that there is an anatomical alteration in the memory over time. What is the nature of this circuit-based consolidation of memory (“systems consolidation") (Squire et al. 2015)? What is the anatomical locus of hippocampaldependent new memories and hippocampalindependent older, consolidated, memories? What is the role of the hippocampus and cortex in the encoding and retrieval of new and old memories? These questions will also resurface below in our discussion of episodic retrieval in humans. The current view of this process posits that during initial encoding and retrieval of an explicit memory, the hippocampus plays a critical role, for example, by encoding an index or map that helps recruit the appropriate cortical regions and specific neural ensembles for recall. 
Over time, these cortical ensembles may become independent of the hippocampus, possibly by strengthening their connectivity through postlearning replay of relevant activity patterns (Wilson and McNaughton 1994), such that with the newly strengthened cortical connections the memory, or at least some processed versions of it, can be retrieved independently of the hippocampus.

The evidence in rodents for this view of consolidated memories comes from lesion and inactivation of specific brain regions and from studies of the neural activity recruited during retrieval of recent and remote memories. One prediction of the classic memory consolidation model is that, although the hippocampus is important in recent memory retrieval, cortical areas should instead be required for remote memory retrieval, or possibly recent and remote retrieval. This has been tested in the consolidation of three different explicit memory paradigms in rodents: spatial memory, contextual memory, and an olfactory-based social memory (Bontempi et al. 1999; Frankland et al. 2004; Frankland and Bontempi 2005). In all three studies, hippocampal lesions impaired recent memory retrieval ( 1 day posttraining) but spared remote retrieval (30 days posttraining) as expected for hippocampus-dependent tasks involving consolidation. For contextual fear and spatial memories, inactivation of the anterior cingulate cortex produced an impairment in remote memory retrieval but did not affect recent memory, the opposite profile to what is observed with hippocampal inactivation or lesion (Kim and Fanselow 1992; Anagnostaras et al. 1999). A similar result was seen with prefrontal inactivation in the spatial task, while in the olfactorybased social task, inactivation of the orbital frontal cortex impaired both recent and remote memory retrieval.

In addition to inactivation and lesions to probe the anatomical structure of recent and remote memories in rodents, these studies also examined the neural activation patterns during retrieval using IEG expression. In each behavioral paradigm, the activation of the hippocampus was greater with retrieval of recent as opposed to remote memories. Conversely, a wide variety of cortical areas showed increased activity during the retrieval of remote relative to recent memories. Although these studies support the view that remote memories require an increased cortical role in processing, they also raise some questions regarding the initial model of hippocampal coordination of cortical activity during retrieval of recent memory. If, during recent memory retrieval, the hippocampus is coordinating and recruiting cortical activity, then why are these regions often not required for retrieval at this time point and why is there altered cortical activity over time. This suggests that there may be a more fundamental alteration in the circuitry and nature of these memories over time. This is evident at the behavioral level as studies in mice (and humans) have shown that remote memories lose some specificity (Wiltgen and Silva 2007; Winocur et al. 2010; Furman et al. 2012).

One recent study in the mouse has examined the cortical representation of explicit memory using tagging of behaviorally active neural ensembles with ChR2 (Cowansage et al. 2014). In experiments similar to those described above for the DG, ChR2 expression was driven into neurons that were activated during context fear leaning. The investigators examined the retrosplenial cortex, a cortical output area of the hippocampus that is required for encoding and retrieval of both recent and remote contextual memory (Keene and Bucci 2008a,b; see also human studies below). They found that artificial stimulation of the learning-activated ensemble (via ChR2) produced a freezing response suggesting that it instantiated a recall event similar to what was seen in the hippocampal studies. This shows a contextual representation capable of producing retrieval forms in the cortex, in addition to the hippocampus, at the time of learning. More surprisingly, they found that the artificial stimulation of these retrosplenial cortex ensembles produced fear recall even when the hippocampus was pharmacologically silenced 1 day after training, a time point when the hippocampus is still required for natural retrieval of contextual memories. These results show not only that a cortical representation for context memory forms at the time of learning 
A. Ben-Yakov et al.

but the normal requirement for the hippocampus in recall can be bypassed by direct activation of this representation. This finding is consistent with the view of the hippocampus as a map or index that recruits the appropriate cortical circuits during memory retrieval but does not directly store a necessary component of the consolidated representation itself.

The experiments using ChR2 to reactivate neural ensembles that were naturally activated during learning provide important information on how the brain stores and represents complex information about the external world. However, it may be incorrect to characterize these neurons as the "engram" or engram-containing neurons as has sometimes been suggested. The term engram refers to the physical changes in the brain that underlie memory (Semon 1904; Lashley 1950). If we take context conditioning as an example, the conditioning box is initially neutral and exposure produces exploratory behavior. When paired with footshock, the same chamber now causes animals to express a fear response. The engram for this memory would be the sites within the brain that lead the same sensory information (the cues in the box) to be processed in a way that produces fear rather than exploratory behavior, for example, by routing the information to activate the amygdala. The stimulation of ChR2 ensembles at any point in the pathway for processing the sensory information of the context might be expected to represent, and therefore substitute for, the context, without actually being the critical site of plasticity required to produce the processing to fear circuits (the engram). For example, if the retina could be artificially stimulated in precisely the same manner as when an animal explored the context then it might be expected to produce a fear response in conditioned animals in the same way as the experiments discussed above but without carrying the "engram" for that memory.

The study of memory in invertebrates sets up a solid conceptual framework for understanding information processing by nervous systems. Sensory input is processed to different motor/behavioral output based on experience and via plastic changes at specific nodes in the processing network. The mammalian brain introduces a 4 (mouse)- to 7 (human)-order of magnitude increase in the number of neurons between the input and output nodes, but a deep understanding of mammalian memory and retrieval will still require identifying how this information flows through and is represented in the nervous system and the specific sites that are altered with experience to produce the retrievable memory. We have introduced some of the techniques used in mice and rat models and results that suggest a framework for probing this processing at a fine level focused on specific neural ensembles. The added complexity of the mammalian brain has allowed greater specialization of regions for different processing tasks, and memory/retrieval will likely involve a coordinated interplay of more sparse and distributed networks than in simpler systems. The work in humans involving functional brain imaging and, more recently, electrophysiology, is also beginning to identify some of the principles of these processing networks. These techniques allow the assessment of activity across the entire brain during encoding and retrieval and provide a view of the interactions and functional distinctions of different areas during processing.

\section{MEMORY RETRIEVAL IN THE HUMAN BRAIN}

Our discussion of human memory retrieval will focus on declarative and particularly episodic memory (Squire and Dede 2015). We will start by briefly reviewing aspects of the rich phenomenological analyses of human memory retrieval, which has laid the foundations for much of contemporary research on brain substrates and processes of retrieval. We will then survey current knowledge on human brain circuits that subserve retrieval, and conclude with a brief description of functional models that inform many brain studies of long-term memory retrieval.

\section{Phenomenological Analyses of Human Retrieval Processes}

Contemporary research in the neurobiology of human memory retrieval relies heavily on a rich 
body of research in experimental and cognitive psychology that flourished already half a century ago. This research yielded classifications, models, and questions that are at the forefront of investigation of brain and behavioral mechanisms of retrieval. We will mention only a few examples and then proceed to describe their reflection in brain research.

A major distinction in human declarative retrieval is between recall and recognition. Whereas recall is the reactivation or reconstruction of the internal representation of a target item in the absence of that item, prompted by implicit or explicit cues, recognition is the judgment of previous occurrence in the presence of at least part of the target item. This distinction refers hence both to the test used to probe the memory (i.e., whether in the presence or in the absence of the target item) and to the postulated cognitive underpinning of the memory performance gauged by the test. Recall and recognition were each proposed to involve multiple processes, and these processes themselves were further dissociated. In brief, recall was initially posited by some to consist of two major phases, a "generation phase" followed by a recognition phase (Bahrick 1970; Kintsch 1970; Anderson and Bower 1972). Similarly, "dual-process" models of recognition maintain that recognition judgments can be based on two distinct types of memory, familiarity and recollection (James 1890; Mandler 1980; Jacoby and Dallas 1981; Yonelinas 1994; Diana et al. 2006; Voss and Paller 2010). Multiple experimental paradigms have been used to dissociate the two processes (Yonelinas 2002), probing either a subjective sense of recollection ( participants indicate whether they recollect an item, or find it familiar in the absence of specific recollection [Tulving 1985]), or the objective ability to recollect additional aspects of the study event, such as the context in which it was learned ("source memory") or an item associated with the probe during learning.

Although many investigators agree on the existence of two distinct recognition processes (but see Shimamura 2010, for a single-process model), there remain several contentious debates. The first of these pertains to the nature of the recollection signal and how recollection and familiarity ultimately contribute to the recognition judgment. The two leading classes of models, each based on both behavioral and functional neuroimaging evidence, differ primarily with respect to their view of recollection as either a threshold process or as a continuous variable. According to the dual-process, signaldetection model (Yonelinas 1994, 2002; Parks and Yonelinas 2007), familiarity and recollection are two independent processes initiated in parallel. Familiarity is considered to reflect a continuous measure of memory strength, best modeled as a signal-detection process. Conversely, recollection is considered to be a threshold process, whereby only items falling above a certain threshold will be recollected, resulting in relatively high-confidence responses (Yonelinas et al. 2010).

According to an alternate approach, recollection is also a continuous measure that is best modeled by a signal-detection process, and recognition judgments are based on an aggregated memory-strength variable (Rotello et al. 2004; Wixted 2007; Mickes et al. 2009; Wixted and Mickes 2010). The continuous dual-process model (Wixted and Mickes 2010) maintains that, during the process of recognition, recollection and familiarity each elicit a separate internal measure along a memory strength axis. The decision criterion for identifying an item as recognized may be based either on one of these axes, or on an aggregated memory-strength axis, which takes into account both the sense of recollection and the sense of familiarity, depending on the task at hand. The different approaches start to converge, with suggestions that recollection may be graded based on the amount of recollected information (Rugg et al. 2012), but still subject to a threshold-like process (Yonelinas and Jacoby 2012).

Another point of dispute is whether the tests typically used to dissociate recollection and familiarity (e.g., remember/know test [Tulving 1985]) indeed dissociate these two processes (e.g., Perfect 1996; Yonelinas 2002; Parks and Yonelinas 2007; Yonelinas et al. 2010), or whether they in fact only separate strong memories from weaker ones (Donaldson 1996; Dunn 
A. Ben-Yakov et al.

2004; Wais et al. 2008; Wixted et al. 2010). Last, but clearly not least, in the context of the present discussion, the debates involve the role of distinct brain regions, primarily in the medial temporal lobe (MTL) in recollection/familiarity processes (see below).

We selected as an example the recollection/ familiarity debate as it is currently one of the more heated topics in research on episodic memory retrieval (Voss and Paller 2010). However, it is noteworthy that this far from covers the research into the phenomenology, and ultimately candidate brain mechanisms, of human memory retrieval. An additional distinction is drawn between the content of retrieval and the entering of a state that enables retrieval ("retrieval mode" [Tulving 1983], see Rugg and Wilding 2000, for a more fine-grained fractionation), or more generally between different types of item-specific and item-invariant processes in retrieval (e.g., Nyberg et al. 1995; Buckner et al. 1998; Köhler et al. 1998; Dobbins and Wagner 2005; Duarte et al. 2011; Bergström et al. 2013). Further, different types of memories have been shown to involve different retrieval processes, for example, when comparing autobiographical and laboratory-based memories (Cabeza et al. 2004; Svoboda et al. 2006; McDermott et al. 2009), field versus observer perspective (Eich et al. 2009), objective versus subjective measures of recollection (see Spaniol et al. 2009 for a meta-analysis) and emotional versus neutral memories (Maratos and Rugg 2001; LaBar and Cabeza 2006; Buchanan 2007). Although this limited discussion does not allow for a comprehensive review of the fine-grained analysis of the phenomenology of human retrieval, it is important to bear in mind that the rich differentiation of retrieval process has been shown to manifest in differential brain activity during retrieval, emphasizing the notion that retrieval cannot be investigated as a unitary construct.

\section{Substrates of Retrieval in the Human Brain}

As found in rodents, brain circuits of human explicit retrieval are highly distributed (Maguire et al. 2000; Svoboda et al. 2006; Spaniol et al. 2009; Kim et al. 2010; Mendelsohn et al. 2010).
We will briefly review the role of only a few of the major brain areas involved and their interactions in human episodic retrieval, while relating them to some of the postulated subprocesses of retrieval mentioned earlier.

\section{Hippocampus and MTL}

Much of the emphasis in the study of episodic retrieval has been placed on the roles of the MTL (Squire and Dede 2015), specifically differentiating between the hippocampus and surrounding cortices. As focal damage to the fornix and mammillary bodies results in impaired performance that resembles that of hippocampal damage (Dusoir et al. 1990; Tsivilis et al. 2008; Rudebeck et al. 2009; Vann et al. 2009b), it has been suggested the study of hippocampusbased memory should be extended to include the fornix and mammillary bodies as part of the "extended hippocampal system" (Aggleton and Brown 1999).

One approach to differentiating hippocampal versus MTL cortical contributions to retrieval is based on the aforementioned recollection/ familiarity distinction. Several studies have addressed the question of whether the hippocampus is uniquely involved in recollection, or whether it supports both familiarity and recollection (Brown and Aggleton 2001; Eichenbaum et al. 2007; Skinner and Fernandes 2007; Squire et al. 2007; Wixted and Squire 2011; Rugg et al. 2012; Rugg and Vilberg 2013). Both viewpoints are based on findings from studies in patients with MTL damage combined with functional neuroimaging results in healthy subjects.

Whereas many studies report a disproportionate effect of hippocampal damage on recollection and associative memory relative to familiarity (Huppert and Piercy 1978; VarghaKhadem et al. 1997; Holdstock et al. 2002; Yonelinas et al. 2002; Giovanello et al. 2003; Mayes et al. 2004; Aggleton et al. 2005), other reports find that hippocampal damage impacts familiarity and recollection to a similar extent (Manns and Squire 1999; Stark et al. 2002; Manns et al. 2003; Cipolotti et al. 2006; Wais et al. 2006; Jeneson et al. 2010; Kirwan et al. 2010; Song et al. 2011). Interestingly, a patient 
with significant perirhinal damage that spared the hippocampus showed impaired familiarity and preserved recollection (Bowles et al. 2007). Such studies indicate a causal role of MTL regions in the different processes, yet do not allow for dissociation between encoding, storage and retrieval, nor do they necessarily reflect memory processes in the healthy brain.

Conversely, functional magnetic resonance imaging (fMRI) studies do not allow for demonstration of causality, but they enable targeted investigation of correlation with different stages of memory. However, even in fMRI studies focusing on retrieval processes, incidental encoding during retrieval tasks may hinder the ability to tease apart encoding and retrieval processes (Buckner et al. 2001; Stark and Okado 2003; Kim 2013; but, see Staresina et al. 2012b; BenYakov et al. 2014 for temporal dissociations between encoding and retrieval). As with the patient studies, fMRI studies have led to divergent results regarding hippocampal involvement in recollection. One set of studies finds that the hippocampus subserves recollection, but not familiarity, of memoranda such as words or pictures (Eldridge et al. 2000, 2005; Weis et al. 2004; Wheeler and Buckner 2004; Yonelinas et al. 2005; Montaldi et al. 2006; Diana et al. 2007, 2010; Cohn et al. 2009; Ford et al. 2010; Rugg et al. 2012; Yu et al. 2012). More specifically, the hippocampus has been found to respond more strongly to words or pictures reported as "remembered" (Eldridge et al. 2000, 2005; Wheeler and Buckner 2004; Yonelinas et al. 2005; Montaldi et al. 2006), in correct versus incorrect retrieval of the encoding context (Weis et al. 2004; Tendolkar et al. 2008; Duarte et al. 2011; see Staresina et al. 2012b for a related intracranial electroencephalography [iEEG] study), and in associative relative to nonassociative recognition (Kirwan and Stark 2004) or recognition of compound words (Ford et al. 2010). Recent studies propose that hippocampal activity is not related to the subjective sense of recollection, but modulated by the amount of contextual information actually retrieved (Rugg et al. 2012; Yu et al. 2012).

According to an alternate view, the hippocampus is not preferentially involved in recol- lection versus familiarity when controlling for memory strength at the time of the retrieval test (Wais 2008; Wais et al. 2010; Smith et al. 2011; see Montaldi et al. 2006 for opposite results). Wixted and colleagues suggest that the hippocampus and perirhinal cortex are involved in both familiarity and recollection (Squire et al. 2007), but that the hippocampus supports strong memories, whereas the perirhinal supports weak memories (see Wais 2008 for a meta-analysis). However, they propose that memory strength is itself not the parameter that differentiates the hippocampus from the surrounding structures, but rather that different MTL structures process attributes of the memory that are differentially expressed in strong versus weak memories. According to this view, the hippocampus supports both recollectionbased and familiarity-based recognition of multiattribute stimuli, and its involvement in retrieval is most evident for strong memories (Wixted and Squire 2011). Despite the differing interpretations with respect to recollection/familiarity, overall, the hippocampus appears to be primarily involved in the retrieval of strong, rich, multiattribute memories, whereas the surrounding cortices can support retrieval of more simple memories without hippocampal involvement.

Recollection/familiarity are often used in the human literature to describe both the behavioral phenomena and the patterns of brain activity correlated with these phenomena, although there may not necessarily exist a oneto-one mapping between the two types of measures (Voss and Paller 2010). A key example is the finding that the perirhinal cortex is involved in associative memory recognition under conditions of unitization, in which the associated elements comprise a unitized item (Diana et al. 2010; Ford et al. 2010), whereas the hippocampus is preferentially involved in recognition of nonunitized versus unitized pairs (Quamme et al. 2007; Ford et al. 2010). This has been interpreted either as evidence that familiarity can support associative recognition when the paired associates can be bound into a compound unit (Ford et al. 2010; Ranganath 2010) or as evidence that the perirhinal cortex 
A. Ben-Yakov et al.

is involved in recollection of unitized pairs ( $\mathrm{Di}$ ana et al. 2010; Wixted and Squire 2011). Similarly, findings of hippocampal neurons sensitive to picture novelty/oldness (Fried et al. 1997; Rutishauser et al. 2006, 2008; Viskontas et al. 2006) have been subject to differing interpretations, as it is not clear how neuronal sensitivity to familiarity relates to familiarity at the behavioral level (Parks and Yonelinas 2007; Wixted 2007).

The attempts to delineate the role of hippocampus in recollection versus familiarity rest on the assumption that the hippocampus honors the well-established behavioral dissociation between these two manifestations of retrieval. However, there is an increasing view that the behavioral distinction between recollection and familiarity does not reflect the underlying basic computational role(s) of the hippocampus and its surrounding cortices (Diana et al. 2010; Ranganath 2010; Voss and Paller 2010; Wixted and Squire 2011; Rugg et al. 2012). An alternate approach to interpreting the findings reviewed above is that the hippocampal formation plays a role in the binding items in their context (Diana et al. 2007; Eichenbaum et al. 2007; Ranganath 2010). This postulated role also introduces a functional distinction between perirhinal and parahippocampal cortices, according to which the perirhinal cortex encodes item information, the parahippocampal cortex encodes contextual information, and the hippocampus encodes item-context associations as well as item-item associations. A related view (Montaldi and Mayes 2010) assigns to the perirhinal cortex a role in item-memory and within-domain inter-item associations. All of these models emphasize the role of the hippocampus in retrieval of bound associations relative to single item/context recognition, which are supported by the surrounding cortices. They can also be considered in line with the view, mentioned above in discussing the rodent work, that the hippocampus serves as a map or index that recruits the appropriate cortical circuits.

The aforementioned models predict a role for perirhinal cortex in recognition of single items. This is supported by fMRI studies that find decreased perirhinal activity for highly familiar stimuli (Weis et al. 2004; Gonsalves et al. 2005; Daselaar et al. 2006a; Montaldi et al. 2006; although see Kirwan and Stark 2004 for increased perirhinal activity in response to correct associative recognition), as well as an intracranial recording study that found reduced firing in response to familiar images in perirhinal cortex (Viskontas et al. 2006). A study combining iEEG in patients with fMRI in healthy controls (Staresina et al. 2012b) paints a more complex picture. In this study, the perirhinal cortex showed both an early-item novelty effect (differential response to novel vs. familiar words, potentially reflecting a familiarity process) and a sustained source retrieval effect (differential response to correct vs. incorrect retrieval of the context associated with the word). The hippocampus showed an early source retrieval effect, followed by a late-item novelty effect (potentially underlying encoding of the novel item). These studies show a clear role of perirhinal cortex in the recognition of familiar stimuli.

All in all, these different views converge on a predominant role of the hippocampus in associative retrieval. In addition to the functional division between the hippocampus and surrounding cortices, a within-hippocampus functional dissociation has also been suggested, with anterior hippocampus more involved in encoding and posterior hippocampus more involved in retrieval (Lepage et al. 1998; Strange et al. 1999; Spaniol et al. 2009; Poppenk et al. 2013; but see Schacter and Wagner 1999; Ludowig et al. 2008). High-resolution fMRI (Carr et al. 2010) enables an alternate distinction, between the different hippocampal subfields. The few studies available at the time of writing seem to reveal a dissociation between encoding processes observed in DG/CA3 and retrieval (or recollection) in CA1/subiculum (Zeineh et al. 2003; Eldridge et al. 2005; Viskontas et al. 2009).

\section{"Default Mode" Network}

A set of regions consisting of the medial prefrontal cortex (mPFC), posterior cingulate, in- 
ferior parietal lobule, lateral temporal cortex, and MTL, has been identified as preferentially active in situations in which external stimuli are absent. This set of regions has therefore been named the "rest" or "default mode" network (Raichle et al. 2001; Buckner et al. 2008; Raichle 2010). Multiple functions have been attributed to the default network, including stimulus-independent mental processes ("mind wandering"; Mason et al. 2007), mental scene construction (Hassabis and Maguire 2007) and self-projection into the future/past (Addis et al. 2007; Buckner and Carroll 2007).

There is a remarkable overlap between the network activated in retrieval of autobiographical memory (Svoboda et al. 2006; McDermott et al. 2009) and the default network (Buckner et al. 2008). Further, a recent study of patients with focal lesions in regions within the default network showed correlation of damage to this network with disruption of autobiographical memory retrieval (Philippi et al. 2015). Whereas deficits in semantic elements of autobiographical memory were associated with damage to the left mPFC and MTL, deficits to episodic autobiographical memory were associated with damage to the right MPFC and MTL. A metaanalysis study (Spreng et al. 2009) that compared default mode regions with activations of autobiographical memory retrieval, prospection (imagining oneself in the future), navigation, and intentionality ("theory of mind") found significant overlap between most of the different functions. Retrieval, prospection, and theory of mind tasks all activated similar default mode regions, including multiple prefrontal, parietal, and temporal regions. The abundance of evidence linking episodic retrieval to mental construction or simulation of future/fictitious events (Hassabis and Maguire 2007, 2009; Hassabis et al. 2007; Schacter and Addis 2007; Schacter et al. 2008; Buckner 2010; Rabin et al. 2010; Szpunar 2010; Viard et al. 2012) has led to a renewed emphasis on the constructive nature of memory (Bartlett 1932).

Investigation of the commonalities versus the differences between episodic retrieval, which is mental time travel to the past, and mental time travel to the future (imagination), have enabled dissociation between purely mnemonic components and processes relating more generally to construction of episodes (Addis et al. 2007, 2009; Weiler et al. 2010; Addis and Schacter 2011; Schacter et al. 2012). Notably, the hippocampus, which is coupled with the default network at retrieval (Huijbers et al. 2011), is one of the main regions implicated in tasks that require the participant to imagine future scenarios (Addis and Schacter 2011; Schacter et al. 2012; Maguire and Mullally 2013).

\section{Prefrontal Cortex}

The prefrontal cortex (PFC), subregions of which were mentioned above in the context of the "default network," was one of the first regions linked to episodic memory retrieval in functional neuroimaging studies (Fig. 2A) (Nyberg et al. 1995; Buckner et al. 1998; Rugg et al. 1998; Wagner et al. 1998; Düzel et al. 1999; Lepage et al. 2000), in line with studies revealing memory impairment in patients with frontal lobe damage (e.g., Luria 1966; Stuss et al. 1994; Wheeler et al. 1995; Duarte et al. 2005; Aly et al. 2011). Different regions of the PFC have been implicated in mnemonic processes that support retrieval, particularly in domaingeneral processes, such as setting the retrieval mode or orientation, initiating the retrieval attempt, monitoring, goal-directed manipulation of retrieved information and overcoming of interference (Shimamura 1995; Rugg et al. 1996; Moscovitch and Winocur 2002; Badre and Wagner 2007; Blumenfeld and Ranganath 2007). Several functional divisions of the PFC have been suggested, from the original hemispheric encoding/retrieval asymmetry (HERA) model that proposed preferential right PFC involvement in retrieval (Tulving et al. 1994; Habib et al. 2003; see Cabeza et al. 2003 for an alternate hypothesis regarding the roles of left/ right $\mathrm{PFC}$ in retrieval), to within-hemispheric divisions according to medial/lateral, anterior/ posterior and dorsal/ventral axes attributing specific mnemonic processes to each subregion (Fletcher and Henson 2001; Wagner et al. 2001; Petrides 2002; Simons et al. 2005; Badre and Wagner 2007). 
A. Ben-Yakov et al.

A

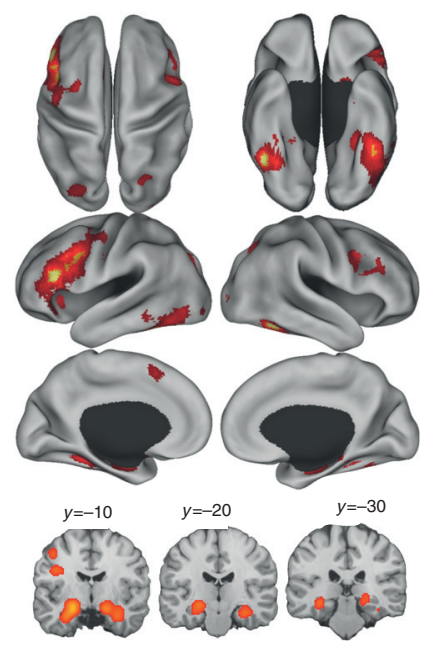

B

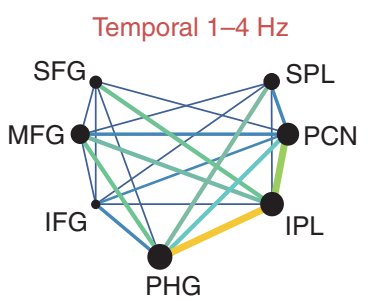

Spatial $1-4 \mathrm{~Hz}$

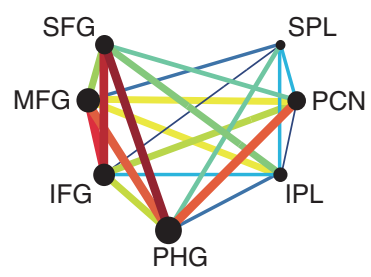

Temporal $7-10 \mathrm{~Hz}$

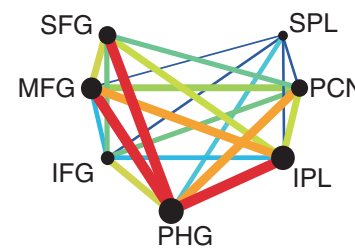

Spatial $7-10 \mathrm{~Hz}$

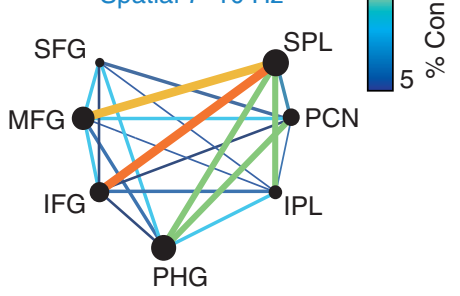

Figure 2. Brain correlates of retrieval of human declarative memory. (A) Brain network associated with recognition memory. The figure depicts a meta-analysis of areas that show old $>$ new activation in recognition tests in $38 \mathrm{fMRI}$ (functional magnetic resonance imaging) studies. The regions identified include the, angular gyrus, caudate nucleus, dorsolateral prefrontal cortex (DLPFC), dorsomedial prefrontal cortex, dorsal posterior parietal cortex, posterior cingulate cortex, and precuneus. (Based on data in Kim 2013; with permission from the author.) (B) Diagrams depicting the dynamics of brain network fast functional connectivity in memory retrieval revealed by electrocorticographical $(\mathrm{ECoG})$ recording in patients undergoing seizure monitoring. The patients were engaged in retrieving spatial and temporal episodic contexts. Phase synchronization between brain areas was used as a measure of connectivity. The panels display the connectivity correlated with correct spatial and temporal retrieval in the $1-4 \mathrm{~Hz}$ and $7-10 \mathrm{~Hz}$ bands. PHG, Parahippocampal gyrus; MFG, middle frontal gyrus; SFG, superior frontal gyrus; IFG, inferior frontal gyrus; IPL, inferior parietal lobule; PCN, precuneus; SPL, superior parietal lobule. Successful retrieval was associated with greater global connectivity among the sites with the medial temporal lobe (MTL) acting as a hub for the interactions, but whereas correct spatial context retrieval was characterized by lower frequency interactions across the network, temporal context retrieval was characterized by faster frequency interactions. These results provide insight into how multiple contexts associated with a single event can be retrieved in the same network. (Based on data in Watrous et al. 2013; with permission from the authors.)

A meta-analysis comparing encoding and recollection found that both encoding and retrieval of memoranda such as pictures and words primarily activated the left PFC, in contradiction to the HERA model (Spaniol et al. 2009). A comparison between objective/ subjective recollection revealed stronger activation for objective recollection in ventrolateral PFC (VLPFC) and dorsolateral PFC (DLPFC) and lateral anterior PFC and stronger activation for subjective recollection in medial anterior PFC, in line with suggested roles for lateral PFC in cognitive control of memory (Simons and Spiers 2003; Badre and Wagner 2007) and medial PFC in self-referential processing (Northoff et al. 2006).

\section{Posterior Parietal Cortex}

In contrast to the functional neuroimaging findings concerning MTL and PFC, there is a striking inconsistency between findings of posterior parietal cortex involvement in retrieval and studies of patients with parietal lesions. Functional neuroimaging studies consistently observed parietal activations in episodic retrieval tasks (Shannon and Buckner 2004; Wagner et al. 2005; Vilberg and Rugg 2008; Hutchinson et al. 2009; Spaniol et al. 2009), with the ventral posterior parietal cortex involved primarily in recollection, and the dorsal posterior parietal involved more generally in recognition (Shannon and Buckner 2004; Wagner et al. 2005; Vil- 
berg and Rugg 2007, 2008, 2012). Conversely, most lesion studies find limited, if any, impairment in episodic retrieval (Berryhill et al. 2007, 2010; Haramati et al. 2008), supported by an repetitive transcranial magnetic stimulation (rTMS) study that found disruption of the posterior parietal cortex does not significantly impair memory (Rossi et al. 2006). A study directly comparing patients lesioned in this cortex with fMRI of healthy individuals found an anatomical overlap between the parietal recollection-related activations and the locus of the damage in patients that showed normal performance on the same task (Simons et al. 2008). The robust parietal involvement in intact recollection taken together with the relatively subtle impairments yielded by damage to this cortex have led to several models regarding its role in memory, particularly in attention to memory (Cabeza et al. 2008, 2012; Ciaramelli et al. 2008), in serving as a short-lived episodic buffer (Vilberg and Rugg 2008; Wagner et al. 2005), and in binding relational activity (Shimamura 2011).

\section{Additional Contributions to the Retrieval Network}

We focused so far on the region's most commonly identified with human episodic memory retrieval, yet additional brain regions have also been implicated in episodic retrieval. The thalamus, in particular, the anterior thalamic nuclei, has received particular attention because of their connections with the hippocampus. Aggleton and Brown (1999) suggested that the anterior thalamic nuclei and mammillary bodies are necessary for recollection, whereas the medial dorsal nucleus supports familiarity. A recent review (Aggleton et al. 2011) supports this proposal only in part. Damage to anterior thalamic nuclei, which are connected to the hippocampus and mammillary bodies, has been shown to impair recognition memory, although the impairment is significantly less severe than damage to the hippocampus or mammillary bodies. An fMRI study identified a linear increase of activity in the dorsomedial thalamus in response to pictures eliciting a stronger sense of familiarity (Montaldi et al. 2006), yet it is unclear whether damage to this nucleus directly impairs recognition. An additional region that has received renewed interest is the retrosplenial cortex (see also rodent studies above). Although the retrosplenial cortex is consistently activated in studies of autobiographical retrieval, and damage to the region impairs retrieval of recent episodic memories, its role in memory was originally thought to be indirect (Vann et al. 2009a). Specifically, this cortex is preferentially involved in recollection of recent (Gilboa et al. 2004) and selfrelevant memories (Summerfield et al. 2009), and it has been suggested to support translation from egocentric to allocentric views (Byrne et al. 2007). Taken together, these findings suggest a role for the retrosplenial cortex in semantization of episodic memories, which may entail a shift to a more allocentric representation of the memory. The striatum, traditionally linked to nondeclarative memory, has also become a focus of studies in the context of declarative memory retrieval, and it has been suggested to support cognitive control of episodic retrieval in concert with the PFC (Scimeca and Badre 2012).

Cabeza and Moscovitch (2013) propose that each memory task recruits a different combination of processing components, some of which are likely to be shared by nonmemory tasks as well. The set of processing components that interact to support a given task, for example, retrieval of an episodic memory, is denoted a "process-specific alliance," underlining the effect of transient interregional interactions on the contribution of individual brain regions to the task at hand. In the context of our discussion, this emphasizes the importance of understanding not only the role of each brain region in retrieval, but also how different regions interact to support distinct mnemonic functions, including retrieval (Simons and Spiers 2003; Mendelsohn et al. 2010; Cabeza et al. 2011; Huijbers et al. 2011; St Jacques et al. 2011; Fornito et al. 2012; Watrous et al. 2013). Further, the notion that the same region could also be involved in nonmnemonic tasks, may at times blur the distinction between brain signatures of 
A. Ben-Yakov et al.

perception and retrieval, a possibility hinted above in the discussion of recent data on artificial activation of candidate engrams in the rodent brain.

\section{Distributed Interactions in Retrieval}

fMRI studies have shown that, during retrieval, the interactions between distal brain regions is modulated by the type of memory retrieved (Maguire et al. 2000; Greenberg et al. 2005), the age of the memory (Viard et al. 2010; Söderlund et al. 2012), and its veridicality (Mendelsohn et al. 2010). However, fMRI provides us with only snapshots of brain states, averaged over a period of time that is much longer than that in which the machinery of retrieval functions (see above). Electrophysiological studies in human patients undergoing evaluation before neurosurgery has led to finer spatiotemporal dissection and novel insights into the detailed mechanisms of retrieval in the human brain (Suthana and Fried 2012). A prime example is interregional phase locking. Activated ensembles of neurons show oscillatory patterns of activity, and it has been suggested that synchronization in the oscillation phase between different regions may enable communication and mutual interaction between them (Fries 2005). Further, synchronization at different frequency ranges corresponds to different spatial scales, with synchronization at lower frequencies associated with interactions between more distal regions (Canolty et al. 2010). Thus, phase coupling between low and high frequencies may enable synchronization of local activity in distal brain regions (Canolty et al. 2006; Jacobs et al. 2007; Canolty and Knight 2010; Rutishauser et al. 2010; Maris et al. 2011; van der Meij et al. 2012). In regard to memory, there has been particular interest in the theta band $(3-8 \mathrm{~Hz}$ including "slow theta"), and in theta/gamma (30-150 Hz including "high gamma") coupling, which have been linked to various mnemonic processes of encoding, working memory and long-term memory (Nyhus and Curran 2010; Fell and Axmacher 2011). Specifically, successful memory retrieval has been linked to intraregional increases in theta and gamma os- cillations (Osipova et al. 2006; Gruber et al 2008) unveiled in EEG/MEG as well as phase synchronization between prefrontal, parietal, and medial temporal regions (Anderson et al. 2009; Polanía et al. 2012; Watrous et al. 2013) and phase-amplitude coupling between prefrontal theta and parietal gamma oscillations (Köster et al. 2014).

Beyond the role of these oscillations in enabling interregional synchronization, several models suggest that the theta oscillations could serve to encode specific temporal and spatial contexts (Hasselmo 2012; Watrous et al. 2013, 2015; Hasselmo and Stern 2014). In one recent study, Watrous and colleagues (2013) examined low-frequency $(1-10 \mathrm{~Hz})$ phase synchronization in electrocorticographical recordings from the parahippocampal gyrus, the parietal cortex and lateral prefrontal cortex during retrieval of spatial and temporal information regarding locations previously encountered during virtual navigation. They found an overall increase in presumed network connectivity (measured by phase synchronization) during successful retrieval, primarily centered on the parahippocampal gyrus. When comparing successful retrieval of spatial and temporal context, both were characterized by an increase in network connectivity, yet correct retrieval of spatial context involved lower frequency interactions relative to retrieval of temporal context (Fig. 2B). This suggests a mechanism that could enable simultaneous representation of spatial and temporal contextual information in the same circuit through phase/frequency multiplexing (Watrous et al. 2013, 2015). In addition, theta oscillations may support rapid switching between encoding and retrieval modes in the MTL (Hasselmo et al. 2002; Hasselmo and Stern 2014). This model is also supported by evidence of differing oscillatory phases following study items versus test probes, albeit in a working memory task (Rizzuto et al. 2006).

\section{Reinstatement of Encoding Processes during Retrieval}

A widely presented view of episodic memory retrieval, mentioned above, also in referring to 
rodent studies, is that retrieval entails reinstatement of brain activity that was elicited during encoding (Damasio 1989; McClelland et al. 1995; reviewed in Buckner and Wheeler 2001; Rugg et al. 2008; Danker and Anderson 2010; Rissman and Wagner 2012; Levy and Wagner 2013). Influential data-driven cognitive theories posited that the match between encoding and retrieval cues and between level of processing (e.g., in verbal memoranda) is pertinent for successful retrieval (Tulving and Thomson 1973; Morris et al. 1977). This gives rise to the question of how the representation of a stored memory may relate to the representation of the experience. With the advent of fMRI it became possible to probe this question in the human brain more directly, testing whether retrieval entails reinstatement of specific blood oxygenation level-dependent (BOLD) activity patterns elicited during encoding in distinct brain areas.

Initial studies showed that sensory cortices active at encoding were also active at retrieval (Nyberg et al. 2000, 2001; Wheeler et al. 2000, 2006; Vaidya et al. 2002; Gottfried et al. 2004; Kahn et al. 2004; Wheeler and Buckner 2004; Woodruff et al. 2005). This reactivation was suggested to be related to the subjective experience of recollection (Wheeler and Buckner 2004), for both veridical recollection and false alarms (Kahn et al. 2004). Johnson and Rugg (2007) directly compared the task-specific recollection activity to the brain activity at time of encoding. They found an overlap between brain regions underlying task-specific successful encoding and regions underlying successful recollection of words encoded under the same task (but no cross-task overlap). This set of studies provides compelling evidence in favor of cortical reinstatement, that is, reinstatement of cortical activity patterns elicited at encoding during retrieval of the same event. However, these studies reveal reinstatement only at a rather coarse level, indicating a general overlap between brain regions involved in content-specific encoding and those involved retrieval of the corresponding stimuli. Multivariate approaches for analysis of fMRI data enable more fine-grained tests of reinstatement of specific spatial activity patterns within regions. Traditional fMRI analyses focus on identifying voxels (volumetric pixels) that change their activity in response to certain tasks or cognitive states, testing each voxel in isolation. More recent multivariate approaches, such as multivoxel pattern analysis (Haxby et al. 2001; Norman et al. 2006) and representational similarity analysis (Kriegeskorte et al. 2008), shift the focus to multivoxel patterns of activity, allowing for the identification of reinstatement at a higher spatial resolution.

In the first multivoxel pattern analysis of episodic memory, Polyn et al. (2005) trained a classifier (i.e., an algorithm that enables classification of brain states based on distinct activation patterns) on activity patterns during encoding of pictures in three categories, and were able to predict the category of pictures recalled in a free recall test. Notably, reinstatement of activity patterns during retrieval has been found to occur in the absence of subjective recollection (Johnson et al. 2009) as well as in situations of competing memories (Kuhl et al. 2011, 2012), suggesting that reinstatement may occur even in implicit retrieval. The increased spatial resolution afforded by such multivariate approaches enables investigation of event-specific cortical reinstatement. Two recent studies (Staresina et al. 2012a; Ritchey et al. 2013) were able to identify such item-specific reinstatement. Staresina et al. (2012a) examined whether item-specific neural representations elicited during episodic encoding are later reinstated during successful recollection. They presented participants with word-scene pairs and later tested their memory using the words as cues, measuring brain activity (using fMRI) during both encoding and retrieval. The parahippocampal cortex showed increased similarity between encoding and retrieval activation patterns (encoding-retrieval similarity) during successful recollection. This reactivation was observed only during successful recollection, not during recognition, and was event-specific (i.e., the encoding-retrieval similarity was driven by reinstatement of specific word-scene combinations rather than by the scene itself). Notably, the hippocampal encoding-retrieval similarity was not predictive of memory, but the amplitude of the hip- 
A. Ben-Yakov et al.

pocampal response was correlated with the parahippocampal encoding-retrieval similarity during retrieval, suggesting it may mediate the reinstatement observed in the parahippocampus.

EEG studies have also shown encoding-retrieval overlap (Rösler et al. 1995; Gratton et al. 1997; Khader et al. 2005). Given the low temporal resolution of fMRI, which does not enable comparing the temporal dynamics of the activity at encoding versus retrieval at a resolution finer than several seconds, a promising approach may be to test encoding-retrieval overlap using MEG (Jafarpour et al. 2014) or by combining EEG and fMRI (Khader et al. 2007; see Johnson and Rugg 2007 and Johnson et al. 2008 for two studies using similar protocols with fMRI and EEG, respectively). Eletrophysiological measures obtained from depth electrodes in neurosurgical patients are also used to obtain high temporal resolution data in the investigation of human retrieval. For example, using this approach, Gelbard-Sagiv et al. (2008) showed that episodic recall, using movie clips as memoranda, entails the activation of episodespecific activity patterns in the hippocampus.

Although there is compelling evidence that encoding-related brain activity is partially reinstated during retrieval, the overlapping activity is still a small fraction of the overall brain activity elicited during encoding and retrieval (Johnson and Rugg 2007; Rugg et al. 2008; Daselaar et al. 2009; Kim et al. 2010). This may be caused by several contributing factors (Rugg et al. 2008), such as features of the original experience that may not be encoded, or encoded but not retrieved. In addition, given the reconstructive nature of memory retrieval (Loftus and Palmer 1974; Schacter et al. 1998), additional information, unrelated to the original event, may be incorporated into the representation.

Indeed, false memories have been shown to elicit false reinstatement effects that mimic those of veridical reinstatement (Kahn et al. 2004), in line with findings that the majority of brain regions involved in retrieval are sensitive to the subjective feeling of retrieval rather than the veridicality of retrieval (Mendelsohn et al. 2010; Rissman et al. 2010; Dennis et al.
2012). Interestingly, the main regions found to differentiate true from false memories are in sensory cortices and MTL (Cabeza et al. 2001; Slotnick and Schacter 2004; Daselaar et al. 2006b; Kirwan et al. 2009; Dennis et al. 2012), the same regions that may be expected to show reinstatement.

More generally, dominant models of systems consolidation (see above, also Squire et al. 2015), suggest that memory representations change over time. For example, systems consolidation in humans has been reported to involve semantization of episodic experience (Cermak 1984; Conway et al. 1997; Nadel et al. 2007; Conway 2009; Piolino et al. 2009; Furman et al. 2012). One of the major debates in this regard (see also discussion of rodent studies above) pertains to whether only retrieval of recent memories is dependent on the hippocampus (e.g., Squire et al. 2001; Squire and Bayley 2007; Bartsch et al. 2011), or whether it is required for retrieval of vivid memories, regardless of memory age (Moscovitch et al. 2005, 2006; Hassabis and Maguire 2007; Rosenbaum et al. 2008; Dudai 2012; Bonnici et al. 2013). Evidence from human neuroimaging studies suggests that both vividness and memory age affect different aspects of the hippocampal activity and its connectivity with the cortical retrieval network (e.g., Gilboa et al. 2004; Piolino et al. 2009; Viard et al. 2010; Furman et al. 2012; Harand et al. 2012; Söderlund et al. 2012). Two recent multivoxel pattern analysis studies directly probed how passage of time affects the representation in both hippocampal and cortical regions by decoding specific recent/ remote autobiographical memories (Bonnici et al. 2012, 2013). They found that both vmPFC and hippocampus contained information about recent and remote memories, with more remote information in vmPFC and posterior hippocampus.

Memory representations may also be subject to change when encountering in retrieval novel events that are related to the existing memories (e.g., in reconsolidation; Nader 2015). Such conditions may result in generalization/inference (Moses et al. 2006; Shohamy and Wagner 2008; Kumaran and McClelland 2012), interfer- 
ence (Müller and Pilzecker 1900; Anderson 2003; Wixted 2004), or creation of false memories (Schacter and Slotnick 2004; Loftus 2005). Increasingly sensitive analyses methods of human brain imaging provide improved abilities to probe the interactions between encoding of new information and reactivation of previous representations (Staresina et al. 2012b; Ben-Yakov et al. 2014; Brown et al. 2015).

All in all, the studies described in this section show that episodic memory retrieval in the human brain entails activation of corticohippocampal or cortical representations. Timelocking of transient spatiotemporal patterns of activation in distinct distributed cortical or corticohippocampal ensembles may permit permutational binding of representational elements to yield specific representations, and may also allow different representations to be stored in the same network. These representations are driven largely by the activity during encoding, but they are malleable, subject to the influence of time, semantization, and interaction of the existing memory with novel information.

\section{CONCLUSIONS}

Our brief review of the investigation of memory retrieval in the mammalian brain shows how the combination of multiple levels of analysis, methods, and experimental systems and the introduction of novel techniques have markedly advanced the study of retrieval in recent years. But it also shows how much has yet to be learned. Research on declarative retrieval builds on a rich body of studies in experimental psychology, which has also generated influential models of retrieval and of the relevance of the information retrieved to the information encoded. Studies of brain damage in amnesia have identified brain areas, particularly in the hippocampus and surrounding neocortex, that play a role in both encoding and retrieval, and indicated that the role of these areas changes as the memory consolidates and with the passage of time. However, until recently, the methods available did not allow the spatiotemporal resolution required to dissect the processes involved in retrieval of complex memory, which is accomplished within a fraction of a second. This is now possible, with the introduction of powerful methods in molecular biology, neurogenetics, and in vivo molecular and cellular imaging in rodents. The development of improved noninvasive functional brain imaging in humans, electrophysiology in patients, and more sophisticated data analyses, now also enable teasing apart subprocesses and brain substrates of retrieval of high-level memory unique to humans, such as autonoetic (i.e., involving selfawareness) episodic memory, verbal recollections, and autobiographical memory. The picture that emerges from both rodent and human studies is that retrieval of complex memory involves coordinated fast interplay of sparse and distributed networks, and yet leaves open the question whether some principles and elements of the codes that embody the expressed representations are still unknown.

\section{REFERENCES}

${ }^{*}$ Reference is also in this collection.

Addis DR, Schacter DL. 2011. The hippocampus and imagining the future: Where do we stand? Front Hum Neurosci 5: 173 .

Addis DR, Wong AT, Schacter DL. 2007. Remembering the past and imagining the future: Common and distinct neural substrates during event construction and elaboration. Neuropsychologia 45: 1363-1377.

Addis DR, Pan L, Vu MA, Laiser N, Schacter DL. 2009. Constructive episodic simulation of the future and the past: Distinct subsystems of a core brain network mediate imagining and remembering. Neuropsychologia 47: 2222-2238.

Aggleton JP, Brown MW. 1999. Episodic memory, amnesia, and the hippocampal-anterior thalamic axis. Behav Brain Sci 22: 425-444.

Aggleton JP, Vann SD, Denby C, Dix S, Mayes AR, Roberts N, Yonelinas AP. 2005. Sparing of the familiarity component of recognition memory in a patient with hippocampal pathology. Neuropsychologia 43: 18101823.

Aggleton JP, Dumont JR, Warburton EC. 2011. Unraveling the contributions of the diencephalon to recognition memory: A review. Learn Mem 18: 384-400.

Akerboom J, Chen TW, Wardill TJ, Tian L, Marvin JS, Mutlu S, Calderon NC, Esposti F, Borghuis BG, Sun XR, et al. 2012. Optimization of a GCaMP calcium indicator for neural activity imaging. J Neurosci 32: 13819-13840.

Aly M, Yonelinas AP, Kishiyama MM, Knight RT. 2011. Damage to the lateral prefrontal cortex impairs familiarity but not recollection. Behav Brain Res 225: 297-304. 
Anagnostaras SG, Maren S, Fanselow MS. 1999. Temporally graded retrograde amnesia of contextual fear after hippocampal damage in rats: Within-subjects examination. J Neurosci 19: 1106-1114.

Anderson MC. 2003. Rethinking interference theory: Executive control and the mechanisms of forgetting. J Mem Lang 49: 415-445.

Anderson JR, Bower GH. 1972. Recognition and retrieval processes in free recall. Psychol Rev 79: 97.

Anderson KL, Rajagovindan R, Ghacibeh GA, Meador KJ, Ding M. 2009. Theta oscillations mediate interaction between prefrontal cortex and medial temporal lobe in human memory. Cereb Cortex 20: 1604-1612.

Baddeley AD. 1982. Domains of recollection. Psychol Rev 89: 708.

Baddeley A. 2000. The episodic buffer: A new component of working memory? Trends Cogn Sci 4: 417-423.

Badre D, Wagner AD. 2007. Left ventrolateral prefrontal cortex and the cognitive control of memory. Neuropsychologia 45: 2883-2901.

Bahrick HP. 1970. Two-phase model for prompted recall. Psychol Rev 77: 215.

Bakker A, Kirwan CB, Miller M, Stark CE. 2008. Pattern separation in the human hippocampal CA3 and dentate gyrus. Science 319: 1640-1642.

Bartlett FC. 1932. Remembering: A study in experimental and social psychology. Cambridge University Press, Cambridge.

Bartsch T, Döhring J, Rohr A, Jansen O, Deuschl G. 2011. CA1 neurons in the human hippocampus are critical for autobiographical memory, mental time travel, and autonoetic consciousness. Proc Natl Acad Sci 108: $17562-17567$.

Ben-Yakov A, Rubinson M, Dudai Y. 2014. Shifting gears in hippocampus: Temporal dissociation between familiarity and novelty signatures in a single event. J Neurosci 34: 12973-12981.

Bergström ZM, Henson RN, Taylor JR, Simons JS. 2013. Multimodal imaging reveals the spatiotemporal dynamics of recollection. Neuroimage 68: 141-153.

Berryhill ME, Phuong L, Picasso L, Cabeza R, Olson IR. 2007. Parietal lobe and episodic memory: Bilateral damage causes impaired free recall of autobiographical memory. J Neurosci 27: 14415-14423.

Berryhill ME, Picasso L, Arnold R, Drowos D, Olson IR. 2010. Similarities and differences between parietal and frontal patients in autobiographical and constructed experience tasks. Neuropsychologia 48: 1385-1393.

Blumenfeld RS, Ranganath C. 2007. Prefrontal cortex and long-term memory encoding: An integrative review of findings from neuropsychology and neuroimaging. $\mathrm{Neu}$ roscientist 13: 280-291.

Bonnici HM, Chadwick MJ, Lutti A, Hassabis D, Weiskopf N, Maguire EA. 2012. Detecting representations of recent and remote autobiographical memories in vmPFC and hippocampus. J Neurosci 32: 16982-16991.

Bonnici HM, Chadwick MJ, Maguire EA. 2013. Representations of recent and remote autobiographical memories in hippocampal subfields. Hippocampus 23: 849-854.
Bontempi B, Laurent-Demir C, Destrade C, Jaffard R. 1999. Time-dependent reorganization of brain circuitry underlying long-term memory storage. Nature 400: 671-675.

Bowles B, Crupi C, Mirsattari SM, Pigott SE, Parrent AG, Pruessner JC, Yonelinas AP, Köhler S. 2007. Impaired familiarity with preserved recollection after anterior temporal-lobe resection that spares the hippocampus. Proc Natl Acad Sci 104: 16382-16387.

Brown MW, Aggleton JP. 2001. Recognition memory: What are the roles of the perirhinal cortex and hippocampus? Nat Rev Neurosci 2: 51-61.

* Brown TI, Staresina BP, Wagner AD. 2015. Noninvasive functional and anatomical imaging of the human medial temporal lobe. Cold Spring Harb Perspect Biol 7: 10.1101/ cshperspect.a021840.

Buchanan TW. 2007. Retrieval of emotional memories. Psychol Bull 133: 761.

Buckner RL. 2010. The role of the hippocampus in prediction and imagination. Annu Rev Psychol 61: 27-48.

Buckner RL, Carroll DC. 2007. Self-projection and the brain. Trends Cogn Sci 11: 49-57.

Buckner RL, Wheeler ME. 2001. The cognitive neuroscience of remembering. Nat Rev Neurosci 2: 624-634.

Buckner RL, Koutstaal W, Schacter DL, Dale AM, Rotte M, Rosen BR. 1998. Functional-anatomic study of episodic retrieval. II: Selective averaging of event-related fMRI trials to test the retrieval success hypothesis. Neuroimage 7: 163-175.

Buckner RL, Wheeler ME, Sheridan MA. 2001. Encoding processes during retrieval tasks. J Cogn Neurosci 13: 406415.

Buckner RL, Andrews-Hanna JR, Schacter DL. 2008. The brain's default network. Ann NY Acad Sci 1124: 1-38.

* Byrne JH, Hawkins RD. 2015. Nonassociative learning in invertebrates. Cold Spring Harb Perspect Biol 7: a021675.

Byrne P, Becker S, Burgess N. 2007. Remembering the past and imagining the future: A neural model of spatial memory and imagery. Psychol Rev 114: 340.

Cabeza R. 2008. Role of parietal regions in episodic memory retrieval: The dual attentional processes hypothesis. Neuropsychologia 46: 1813-1827.

Cabeza R, Moscovitch M. 2013. Memory systems, processing modes, and components functional neuroimaging evidence. Perspect Psychol Sci 8: 49-55.

Cabeza R, Rao SM, Wagner AD, Mayer AR, Schacter DL. 2001. Can medial temporal lobe regions distinguish true from false? An event-related functional MRI study of veridical and illusory recognition memory. Proc Natl Acad Sci 98: 4805-4810.

Cabeza R, Locantore J, Anderson N. 2003. Lateralization of prefrontal activity during episodic memory retrieval: Evidence for the production-monitoring hypothesis. J $\operatorname{Cog} n$ Neurosci 15: 249-259.

Cabeza R, Prince SE, Daselaar SM, Greenberg DL, Budde M, Dolcos F, LaBar KS, Rubin DC. 2004. Brain activity during episodic retrieval of autobiographical and laboratory events: An fMRI study using a novel photo paradigm. J Cogn Neurosci 16: 1583-1594.

Cabeza R, Ciaramelli E, Olson IR, Moscovitch M. 2008. The parietal cortex and episodic memory: An attentional account. Nat Rev Neurosci 9: 613-625. 
Cabeza R, Mazuz YS, Stokes J, Kragel JE, Woldorff MG, Ciaramelli E, Olson IR, Moscovitch M. 2011. Overlapping parietal activity in memory and perception: Evidence for the attention to memory model. J Cogn Neurosci 23: 3209-3217.

Cabeza R, Ciaramelli E, Moscovitch M. 2012. Cognitive contributions of the ventral parietal cortex: An integrative theoretical account. Trends Cogn Sci 16: 338-352.

Canolty RT, Knight RT. 2010. The functional role of crossfrequency coupling. Trends Cogn Sci 14: 506-515.

Canolty RT, Edwards E, Dalal SS, Soltani M, Nagarajan SS, Kirsch HE, Berger MS, Barbaro NM, Knight RT. 2006. High gamma power is phase-locked to theta oscillations in human neocortex. Science 313: 1626-1628.

Canolty RT, Ganguly K, Kennerley SW, Cadieu CF, Koepsell K, Wallis JD, Carmena JM. 2010. Oscillatory phase coupling coordinates anatomically dispersed functional cell assemblies. Proc Natl Acad Sci 107: 17356-17361.

Carr VA, Rissman J, Wagner AD. 2010. Imaging the human medial temporal lobe with high-resolution fMRI. Neuron 65: $298-308$.

Cermak LS. 1984. The episodic-semantic distinction in amnesia. In Neuropsychology of memory (ed. Squire LR, Butter N), pp. 55-62. Guilford, New York.

Chadwick MJ, Hassabis D, Weiskopf N, Maguire EA. 2010. Decoding individual episodic memory traces in the human hippocampus. Curr Biol 20: 544-547.

Ciaramelli E, Grady CL, Moscovitch M. 2008. Top-down and bottom-up attention to memory: A hypothesis (AtoM) on the role of the posterior parietal cortex in memory retrieval. Neuropsychologia 46: 1828-1851.

Cipolotti L, Bird C, Good T, Macmanus D, Rudge P, Shallice T. 2006. Recollection and familiarity in dense hippocampal amnesia: A case study. Neuropsychologia 44: 489-506.

Cohn M, Moscovitch M, Lahat A, McAndrews MP. 2009. Recollection versus strength as the primary determinant of hippocampal engagement at retrieval. Proc Natl Acad Sci 106: 22451-22455.

Conway MA. 2009. Episodic memories. Neuropsychologia 47: 2305-2313.

Conway MA, Gardiner JM, Perfect TJ, Anderson SJ, Cohen GM. 1997. Changes in memory awareness during learning: The acquisition of knowledge by psychology undergraduates. J Exp Psychol Gen 126: 393.

Cowansage KK, Shuman T, Dillingham BC, Chang A, Golshani P, Mayford M. 2014. Direct reactivation of a coherent neocortical memory of context. Neuron 84: 432-441.

Damasio AR. 1989. Time-locked multiregional retroactivation: A systems-level proposal for the neural substrates of recall and recognition. Cognition 33: 25-62.

Danker JF, Anderson JR. 2010. The ghosts of brain states past: Remembering reactivates the brain regions engaged during encoding. Psychol Bull 136: 87.

Daselaar SM, Fleck MS, Cabeza R. 2006a. Triple dissociation in the medial temporal lobes: Recollection, familiarity, and novelty. J Neurophysiol 96: 1902-1911.

Daselaar SM, Fleck MS, Prince SE, Cabeza R. 2006b. The medial temporal lobe distinguishes old from new independently of consciousness. J Neurosci 26: 5835-5839.

Daselaar SM, Prince SE, Dennis NA, Hayes SM, Kim H, Cabeza R. 2009. Posterior midline and ventral parietal activity is associated with retrieval success and encoding failure. Front Hum Neurosci 3: 13.

Dennis NA, Bowman CR, Vandekar SN. 2012. True and phantom recollection: An fMRI investigation of similar and distinct neural correlates and connectivity. Neuroimage 59: 2982-2993.

Denny CA, Kheirbek MA, Alba EL, Tanaka KF, Brachman RA, Laughman KB, Tomm NK, Turi GF, Losonczy A, Hen R. 2014. Hippocampal memory traces are differentially modulated by experience, time, and adult neurogenesis. Neuron 83: 189-201.

Diana RA, Reder LM, Arndt J, Park H. 2006. Models of recognition: A review of arguments in favor of a dualprocess account. Psychon Bull Rev 13: 1-21.

Diana RA, Yonelinas AP, Ranganath C. 2007. Imaging recollection and familiarity in the medial temporal lobe: A three-component model. Trends Cogn Sci 11: 379-386.

Diana RA, Yonelinas AP, Ranganath C. 2010. Medial temporal lobe activity during source retrieval reflects information type, not memory strength. J Cogn Neurosci 22: 1808-1818.

Dobbins IG, Wagner AD. 2005. Domain-general and domain-sensitive prefrontal mechanisms for recollecting events and detecting novelty. Cereb Cortex 15: 1768 1778 .

Donaldson W. 1996. The role of decision processes in remembering and knowing. Mem Cognit 24: 523-533.

Duarte A, Ranganath C, Knight RT. 2005. Effects of unilateral prefrontal lesions on familiarity, recollection, and source memory. J Neurosci 25: 8333-8337.

Duarte A, Henson RN, Graham KS. 2011. Stimulus content and the neural correlates of source memory. Brain Res 1373: $110-123$.

Dudai Y. 2002. Memory from A to Z keywords, concepts and beyond. Oxford University Press, Oxford.

Dudai Y. 2012. The endless engram: Consolidations never end. Annu Rev Neurosci 35: 227-247.

Duncan K, Sadanand A, Davachi L. 2012. Memory's penumbra: Episodic memory decisions induce lingering mnemonic biases. Science 337: 485-487.

Dunn JC. 2004. Remember-know: A matter of confidence. Psychol Rev 111: 524.

Dusoir H, Kapur N, Byrnes DP, McKinstry S, Hoare RD. 1990. The role of diencephalic pathology in human memory disorder. Evidence from a penetrating paranasal brain injury. Brain 113: 1695.

Düzel E, Cabeza R, Picton TW, Yonelinas AP, Scheich H, Heinze HJ, Tulving E. 1999. Task-related and item-related brain processes of memory retrieval. Proc Natl Acad Sci 96: $1794-1799$.

Eich E, Nelson AL, Leghari MA, Handy TC. 2009. Neural systems mediating field and observer memories. Neuropsychologia 47: 2239-2251.

Eichenbaum H, Yonelinas AR, Ranganath C. 2007. The medial temporal lobe and recognition memory. Annu Rev Neurosci 30: 123.

Eldridge LL, Knowlton BJ, Furmanski CS, Bookheimer SY, Engel SA. 2000. Remembering episodes: A selective role for the hippocampus during retrieval. Nat Neurosci 3: $1149-1152$. 
Eldridge LL, Engel SA, Zeineh MM, Bookheimer SY, Knowlton BJ. 2005. A dissociation of encoding and retrieval processes in the human hippocampus. J Neurosci 25: 3280-3286.

* Fanselow MS, Wassum KM. 2015. The origin and organization of vertebrate Pavlovian conditioning. Cold Spring Harb Perspect Biol doi: 10.1101/cshperspect.a021717.

Farivar R, Zangenehpour S, Chaudhuri A. 2004. Cellularresolution activity mapping of the brain using immediate-early gene expression. Front Biosci 9: 104-109.

Fell J, Axmacher N. 2011. The role of phase synchronization in memory processes. Nat Rev Neurosci 12: 105-118.

Fletcher PC, Henson RNA. 2001. Frontal lobes and human memory insights from functional neuroimaging. Brain 124: $849-881$.

Ford JH, Verfaellie M, Giovanello KS. 2010. Neural correlates of familiarity-based associative retrieval. Neuropsychologia 48: 3019-3025.

Fornito A, Harrison BJ, Zalesky A, Simons JS. 2012. Competitive and cooperative dynamics of large-scale brain functional networks supporting recollection. Proc Natl Acad Sci 109: $12788-12793$.

Frankland PW, Bontempi B. 2005. The organization of recent and remote memories. Nat Rev Neurosci 6: 119-130.

Frankland PW, Bontempi B, Talton LE, Kaczmarek L, Silva AJ. 2004. The involvement of the anterior cingulate cortex in remote contextual fear memory. Science 304: $881-$ 883.

Fried I, MacDonald KA, Wilson CL. 1997. Single neuron activity in human hippocampus and amygdala during recognition of faces and objects. Neuron 18: 753-765.

Fries P. 2005. A mechanism for cognitive dynamics: Neuronal communication through neuronal coherence. Trends Cogn Sci 9: 474-480.

Furman O, Mendelsohn A, Dudai Y. 2012. The episodic engram transformed: Time reduces retrieval-related brain activity but correlates it with memory accuracy. Learn Mem 19: 575-587.

Gelbard-Sagiv H, Mukamel R, Harel M, Malach R, Fried I. 2008. Internally generated reactivation of single neurons in human hippocampus during free recall. Science 322: 96-101.

Gilboa A, Winocur G, Grady CL, Hevenor SJ, Moscovitch M. 2004. Remembering our past: Functional neuroanatomy of recollection of recent and very remote personal events. Cereb Cortex, 14: 1214-1225.

Giovanello KS, Verfaellie M, Keane MM. 2003. Disproportionate deficit in associative recognition relative to item recognition in global amnesia. Cogn Affect Behav Neurosci 3: 186-194.

Godden DR, Baddeley AD. 1975. Context-dependent memory in two natural environments: On land and underwater. Br J Psychol 66: 325-331.

Gonsalves BD, Kahn I, Curran T, Norman KA, Wagner AD. 2005. Memory strength and repetition suppression: Multimodal imaging of medial temporal cortical contributions to recognition. Neuron 47: 751-761.

Gottfried JA, Smith AP, Rugg MD, Dolan RJ. 2004. Remembrance of odors past: Human olfactory cortex in crossmodal recognition memory. Neuron 42: 687-695.
Gratton G, Corballis PM, Jain S. 1997. Hemispheric organization of visual memories. J Cogn Neurosci 9: 92-104.

Greenberg DL, Rice HJ, Cooper JJ, Cabeza R, Rubin DC, LaBar KS. 2005. Co-activation of the amygdala, hippocampus and inferior frontal gyrus during autobiographical memory retrieval. Neuropsychologia 43: 659-674.

Gruber T, Tsivilis D, Giabbiconi CM, Müller MM. 2008. Induced electroencephalogram oscillations during source memory: Familiarity is reflected in the gamma band, recollection in the theta band. J Cogn Neurosci 20: 1043-1053.

Guzowski JF, McNaughton BL, Barnes CA, Worley PF. 1999. Environment-specific expression of the immediate-early gene Arc in hippocampal neuronal ensembles. Nat Neurosci 2: 1120-1124.

Habib R, Nyberg L, Tulving E. 2003. Hemispheric asymmetries of memory: The HERA model revisited. Trends $\operatorname{Cog} n$ Sci 7: $241-245$.

Haramati S, Soroker N, Dudai Y, Levy DA. 2008. The posterior parietal cortex in recognition memory: A neuropsychological study. Neuropsychologia 46: 1756-1766.

Harand C, Bertran F, La Joie R, Landeau B, Mézenge F, Desgranges B, Peigneux P, Eustache F, Rauchs G. 2012. The hippocampus remains activated over the long term for the retrieval of truly episodic memories. PloS ONE 7: e43495.

Hassabis D, Maguire EA. 2007. Deconstructing episodic memory with construction. Trends Cogn Sci 11: 299-306.

Hassabis D, Maguire EA. 2009. The construction system of the brain. Philos Trans R Soc B Lond B Biol Sci 364: 12631271.

Hassabis D, Kumaran D, Maguire EA. 2007. Using imagination to understand the neural basis of episodic memory. $J$ Neurosci 27: 14365-14374.

Hasselmo ME. 2012. How we remember: Brain mechanisms of episodic memory. MIT Press, Cambridge, MA.

Hasselmo ME, Stern CE. 2014. Theta rhythm and the encoding and retrieval of space and time. Neuroimage 85: 656-666.

Hasselmo M, Bodelón C, Wyble B. 2002. A proposed function for hippocampal theta rhythm: Separate phases of encoding and retrieval enhance reversal of prior learning. Neural Comput 14: 793-817.

Haxby JV, Gobbini MI, Furey ML, Ishai A, Schouten JL, Pietrini P. 2001. Distributed and overlapping representations of faces and objects in ventral temporal cortex. Science 293: 2425-2430.

Holdstock JS, Mayes AR, Roberts N, Cezayirli E, Isaac CL, O'Reilly RC, Norman KA. 2002. Under what conditions is recognition spared relative to recall after selective hippocampal damage in humans? Hippocampus 12: $341-$ 351.

Huijbers W, Pennartz CM, Cabeza R, Daselaar SM. 2011. The hippocampus is coupled with the default network during memory retrieval but not during memory encoding. PLOS ONE 6: e17463.

Huppert FA, Piercy M. 1978. The role of trace strength in recency and frequency judgements by amnesic and control subjects. Q J Exp Psychol 30: 347-354.

Hutchinson JB, Uncapher MR, Wagner AD. 2009. Posterior parietal cortex and episodic retrieval: Convergent and 
divergent effects of attention and memory. Learn Mem 16: $343-356$.

Jacobs J, Kahana MJ, Ekstrom AD, Fried I. 2007. Brain oscillations control timing of single-neuron activity in humans. J Neurosci 27: 3839-3844.

Jacoby LL, Dallas M. 1981. On the relationship between autobiographical memory and perceptual learning. $J$ Exp Psychol Gen 110: 306.

Jafarpour A, Fuentemilla L, Horner AJ, Penny W, Düzel E. 2014. Replay of very early encoding representations during recollection. J Neurosci 34: 242-248.

James W. 1890. The principles of psychology. Dover, New York.

Jeneson A, Kirwan CB, Hopkins RO, Wixted JT, Squire LR. 2010. Recognition memory and the hippocampus: A test of the hippocampal contribution to recollection and familiarity. Learn Mem 17: 63-70.

Johnson JD, Rugg MD. 2007. Recollection and the reinstatement of encoding-related cortical activity. Cereb Cortex 17: 2507-2515.

Johnson JD, Minton BR, Rugg MD. 2008. Content dependence of the electrophysiological correlates of recollection. Neuroimage 39: 406-416.

Johnson JD, McDuff SG, Rugg MD, Norman KA. 2009. Recollection, familiarity, and cortical reinstatement: A multivoxel pattern analysis. Neuron 63: 697-708.

Kahn I, Davachi L, Wagner AD. 2004. Functional-neuroanatomic correlates of recollection: Implications for models of recognition memory. J Neurosci 24: 4172-4180.

Kandel ER, Schwartz JH. 1982. Molecular biology of learning: Modulation of transmitter release. Science 218: 433443.

Keene CS, Bucci DJ. 2008a. Contributions of the retrosplenial and posterior parietal cortices to cue-specific and contextual fear conditioning. Behav Neuurosci 122: 8997.

Keene CS, Bucci DJ. 2008b. Neurotoxic lesions of retrosplenial cortex disrupt signaled and unsignaled contextual fear conditioning. Behav Neurosci 122: 1070-1077.

Kentros CG, Agnihotri NT, Streater S, Hawkins RD, Kandel ER. 2004. Increased attention to spatial context increases both place field stability and spatial memory. Neuron 42: 283-295.

Khader P, Heil M, Rösler F. 2005. Material-specific longterm memory representations of faces and spatial positions: Evidence from slow event-related brain potentials. Neuropsychologia 43: 2109-2124.

Khader P, Knoth K, Burke M, Ranganath C, Bien S, Rösler F. 2007. Topography and dynamics of associative long-term memory retrieval in humans. J Cogn Neurosci 19: 493512.

Kim H. 2010. Dissociating the roles of the default-mode, dorsal, and ventral networks in episodic memory retrieval. Neuroimage 50: 1648-1657.

Kim H. 2013. Differential neural activity in the recognition of old versus new events: An activation likelihood estimation meta-analysis. Hum Brain Mapp 34: 814-836.

Kim JJ, Fanselow MS. 1992. Modality-specific retrograde amnesia of fear. Science 256: 675-677.
Kim H, Daselaar SM, Cabeza R. 2010. Overlapping brain activity between episodic memory encoding and retrieval: Roles of the task-positive and task-negative networks. Neuroimage 49: 1045-1054.

Kintsch W. 1970. Models for free recall and recognition. In Models of human memory, Vol. 124. Academic, New York.

Kirwan CB, Stark CE. 2004. Medial temporal lobe activation during encoding and retrieval of novel face-name pairs. Hippocampus 14: 919-930.

Kirwan CB, Shrager Y, Squire LR. 2009. Medial temporal lobe activity can distinguish between old and new stimuli independently of overt behavioral choice. Proc Natl Acad Sci 106: 14617-14621.

Kirwan CB, Wixted JT, Squire LR. 2010. A demonstration that the hippocampus supports both recollection and familiarity. Proc Natl Acad Sci 107: 344-348.

Köhler S, Moscovitch M, Winocur G, Houle S, McIntosh AR. 1998. Networks of domain-specific and general regions involved in episodic memory for spatial location and object identity. Neuropsychologia 36: 129-142.

Köster M, Friese U, Schöne B, Trujillo-Barreto N, Gruber T. 2014. Theta-gamma coupling during episodic retrieval in the human EEG. Brain Res 1577: 57-68.

Kriegeskorte N, Mur M, Bandettini P. 2008. Representational similarity analysis-connecting the branches of systems neuroscience. Front Systems Neurosci 2: 4. 10.3389/ neuro.06.004.2008

Kuhl BA, Shah AT, DuBrow S, Wagner AD. 2010. Resistance to forgetting associated with hippocampus-mediated reactivation during new learning. Nat Neurosci 13: $501-$ 506.

Kuhl BA, Rissman J, Chun MM, Wagner AD. 2011. Fidelity of neural reactivation reveals competition between memories. Proc Natl Acad Sci 108: 5903-5908.

Kuhl BA, Bainbridge WA, Chun MM. 2012. Neural reactivation reveals mechanisms for updating memory. J Neurosci 32: 3453-3461.

Kumaran D, McClelland JL. 2012. Generalization through the recurrent interaction of episodic memories: A model of the hippocampal system. Psychol Rev 119: 573.

LaBar KS, Cabeza R. 2006. Cognitive neuroscience of emotional memory. Nat Rev Neurosci 7: 54-64.

Lashley KS. 1950. In search of the engram. Symp Soc Exp Biol 4: 454-482.

Lepage M, Habib R, Tulving E. 1998. Hippocampal PET activations of memory encoding and retrieval: The HIPER model. Hippocampus 8: 313-322.

Lepage M, Ghaffar O, Nyberg L, Tulving E. 2000. Prefrontal cortex and episodic memory retrieval mode. Proc Natl Acad Sci 97: 506-511.

Levy BJ, Wagner AD. 2013. Measuring memory reactivation with functional MRI implications for psychological theory. Perspect Psychol Sci 8: 72-78.

Liu X, Ramirez S, Pang PT, Puryear CB, Govindarajan A, Deisseroth K, Tonegawa S. 2012. Optogenetic stimulation of a hippocampal engram activates fear memory recall. Nature 484: 381-385.

Loftus EF. 2005. Planting misinformation in the human mind: A 30-year investigation of the malleability of memory. Learn Mem 12: 361-366. 
Loftus EF, Palmer JC. 1974. Reconstruction of automobile destruction: An example of the interaction between language and memory. J Verbal Learning Verbal Behav 13: 585-589.

Ludowig E, Trautner P, Kurthen M, Schaller C, Bien CG, Elger CE, Rosburg T. 2008. Intracranially recorded memory-related potentials reveal higher posterior than anterior hippocampal involvement in verbal encoding and retrieval. J Cogn Neurosci 20: 841-851.

Luria AR. 1966. Higher cortical functions in man. Basic Books, New York.

Maguire EA, Mullally SL. 2013. The hippocampus: A manifesto for change. J Exp Psychol Gen 142: 1180.

Maguire EA, Mummery CJ, Büchel C. 2000. Patterns of hippocampal-cortical interaction dissociate temporal lobe memory subsystems. Hippocampus 10: 475-482.

Mandler G. 1980. Recognizing: The judgment of previous occurrence. Psychol Rev 87: 252.

Mankin EA, Sparks FT, Slayyeh B, Sutherland RJ, Leutgeb S, Leutgeb JK. 2012. Neuronal code for extended time in the hippocampus. Proc Natl Acad Sci 109: 19462-19467.

Manns JR, Squire LR. 1999. Impaired recognition memory on the doors and people test after damage limited to the hippocampal region. Hippocampus 9: 495-499.

Manns JR, Hopkins RO, Reed JM, Kitchener EG, Squire LR. 2003. Recognition memory and the human hippocampus. Neuron 37: 171-180.

Maratos EJ, Rugg MD. 2001. Electrophysiological correlates of the retrieval of emotional and non-emotional context. J Cogn Neurosci 13: 877-891.

Maris E, van Vugt M, Kahana M. 2011. Spatially distributed patterns of oscillatory coupling between high-frequency amplitudes and low-frequency phases in human iEEG. Neuroimage 54: 836-850.

Mason MF, Norton MI, Van Horn JD, Wegner DM, Grafton ST, Macrae CN. 2007. Wandering minds: The default network and stimulus-independent thought. Science 315: 393-395.

Mayes AR, Holdstock JS, Isaac CL, Montaldi D, Grigor J, Gummer A, Cariga P, Downes JJ, Tsivilis D, Gaffan D, et al. 2004. Associative recognition in a patient with selective hippocampal lesions and relatively normal item recognition. Hippocampus 14: 763-784.

McClelland JL, McNaughton BL, O’Reilly RC. 1995. Why there are complementary learning systems in the hippocampus and neocortex: Insights from the successes and failures of connectionist models of learning and memory. Psychol Rev 102: 419-457.

McDermott KB, Szpunar KK, Christ SE. 2009. Laboratorybased and autobiographical retrieval tasks differ substantially in their neural substrates. Neuropsychologia 47: 2290-2298.

Mendelsohn A, Furman O, Dudai Y. 2010. Signatures of memory: Brain coactivations during retrieval distinguish correct from incorrect recollection. Front Behav Neurosci 4: 18.

Mickes L, Wais PE, Wixted JT. 2009. Recollection is a continuous process implications for dual-process theories of recognition memory. Psychol Sci 20: 509-515.
Montaldi D, Mayes AR. 2010. The role of recollection and familiarity in the functional differentiation of the medial temporal lobes. Hippocampus 20: 1291-1314.

Montaldi D, Spencer TJ, Roberts N, Mayes AR. 2006. The neural system that mediates familiarity memory. Hippocampus 16: 504-520.

Morgan JI, Cohen DR, Hempstead JL, Curran T. 1987. Mapping patterns of $c$-fos expression in the central nervous system after seizure. Science 237: 92-197.

Morris CD, Bransford JD, Franks JJ. 1977. Levels of processing versus transfer appropriate processing. J Verbal Learning Verbal Behav 16: 519-533.

Morris RG, Garrud P, Rawlins JN, O'Keefe J. 1982. Place navigation impaired in rats with hippocampal lesions. Nature 297: 681-683.

Moscovitch M, Winocur G. 2002. The frontal cortex and working with memory. In Principles of frontal lobe function (ed. Stuss DT, Knight RT), pp. 188-209. Oxford University Press, Oxford.

Moscovitch M, Rosenbaum RS, Gilboa A, Addis DR, Westmacott R, Grady C, McAndrews MP, Levine B, Black S, Winocur G, et al. 2005. Functional neuroanatomy of remote episodic, semantic and spatial memory: A unified account based on multiple trace theory. J Anat 207: 3566.

Moscovitch M, Nadel L, Winocur G, Gilboa A, Rosenbaum RS. 2006. The cognitive neuroscience of remote episodic, semantic and spatial memory. Curr Opin Neurobiol 16: 179-190.

* Moser M-B, Rowland DC, Moser EI. 2015. Place cells, grid cells, and memory. Cold Spring Harb Perspect Biol 7: a021808.

Moses SN, Villate C, Ryan JD. 2006. An investigation of learning strategy supporting transitive inference performance in humans compared to other species. Neuropsychologia 44: 1370-1387.

Müller GE, Pilzecker A. 1900. Experimental contributions to the theory of memory. Z Psychol Z Angew Psychol 1: 1288.

Nadel L, Campbell J, Ryan L. 2007. Autobiographical memory retrieval and hippocampal activation as a function of repetition and the passage of time. Neural Plast 2007: 90472.

* Nader K. 2015. Reconsolidation and the dynamic nature of memory. Cold Spring Harb Perspect Biol 7: a021782.

Norman KA, Polyn SM, Detre GJ, Haxby JV. 2006. Beyond mind-reading: Multi-voxel pattern analysis of fMRI data. Trends Cogn Sci 10: 424-430.

Northoff G, Heinzel A, de Greck M, Bermpohl F, Dobrowolny H, Panksepp J. 2006. Self-referential processing in our brain-A meta-analysis of imaging studies on the self. Neuroimage 31: 440-457.

Nyberg L, Tulving E, Habib R, Nilsson LG, Kapur S, Houle S, Cabeza R, McIntosh AR. 1995. Functional brain maps of retrieval mode and recovery of episodic information. Neuroreport 7: 249-252.

Nyberg L, Habib R, McIntosh AR, Tulving E. 2000. Reactivation of encoding-related brain activity during memory retrieval. Proc Natl Acad Sci 97: 11120-11124. 
Nyberg L, Petersson KM, Nilsson LG, Sandblom J, Åberg C, Ingvar M. 2001. Reactivation of motor brain areas during explicit memory for actions. Neuroimage 14: 521-528.

Nyhus E, Curran T. 2010. Functional role of gamma and theta oscillations in episodic memory. Neurosci Biobehav Rev 34: 1023-1035.

O'Keefe J. 1990. A computational theory of the hippocampal cognitive map. Prog Brain Res 83: 301-312.

O'Keefe J, Dostrovsky J. 1971. The hippocampus as a spatial map. Preliminary evidence from unit activity in the freely-moving rat. Brain Res 34: 171-175.

Osipova D, Takashima A, Oostenveld R, Fernández G, Maris E, Jensen O. 2006. Theta and gamma oscillations predict encoding and retrieval of declarative memory. J Neurosci 26: $7523-7531$.

Parks CM, Yonelinas AP. 2007. Moving beyond pure signaldetection models: Comment on Wixted (2007). Psychol Rev 114: 188-202; discussion 203-209.

Perfect TJ. 1996. Does context discriminate recollection from familiarity in recognition memory? Q J Exp Psychol A 49: 797-813.

Petrides M. 2002. The mid-ventrolateral prefrontal cortex and active mnemonic retrieval. Neurobiol Learn Mem 78: $528-538$.

Philippi CL, Tranel D, Duff M, Rudrauf D. 2015. Damage to the default mode network disrupts autobiographical memory retrieval. Soc Cogn Affect Neurosci 10, 318-326.

Piolino P, Desgranges B, Eustache F. 2009. Episodic autobiographical memories over the course of time: Cognitive, neuropsychological and neuroimaging findings. Neuropsychologia 47: 2314-2329.

Polanía R, Nitsche MA, Korman C, Batsikadze G, Paulus W. 2012. The importance of timing in segregated theta phase-coupling for cognitive performance. Curr Biol 22: 1314-1318.

Polyn SM, Natu VS, Cohen JD, Norman KA. 2005. Category-specific cortical activity precedes retrieval during memory search. Science 310: 1963-1966.

Poppenk J, Evensmoen HR, Moscovitch M, Nadel L. 2013. Long-axis specialization of the human hippocampus. Trends Cogn Sci 17: 230-240.

Ritchey M, Wing EA, LaBar KS, Cabeza R. 2013. Neural similarity between encoding and retrieval is related to memory via hippocampal interactions. Cereb Cortex 23: 2818-2828.

Quamme JR, Yonelinas AP, Norman KA. 2007. Effect of unitization on associative recognition in amnesia. Hippocampus 17: 192-200.

Rabin JS, Gilboa A, Stuss DT, Mar RA, Rosenbaum RS. 2010. Common and unique neural correlates of autobiographical memory and theory of mind. J Cogn Neurosci 22: $1095-1111$.

Raichle ME. 2010. Two views of brain function. Trends $\operatorname{Cog} n$ Sci 14: $180-190$.

Raichle ME, MacLeod AM, Snyder AZ, Powers WJ, Gusnard DA, Shulman GL. 2001. A default mode of brain function. Proc Natl Acad Sci 98: 676-682.

Ramirez S, Liu X, Lin PA, Suh J, Pignatelli M, Redondo RL, Ryan TJ, Tonegawa S. 2013. Creating a false memory in the hippocampus. Science 341: 387-391.
Ranganath C. 2010. A unified framework for the functional organization of the medial temporal lobes and the phenomenology of episodic memory. Hippocampus 20: $1263-1290$.

Reijmers LG, Perkins BL, Matsuo N, Mayford M. 2007. Localization of a stable neural correlate of associative memory. Science 317: 1230-1233.

Rissman J, Wagner AD. 2012. Distributed representations in memory: Insights from functional brain imaging. Annu Rev Psychol 63: 101-128.

Rissman J, Greely HT, Wagner AD. 2010. Detecting individual memories through the neural decoding of memory states and past experience. Proc Natl Acad Sci 107: 98499854.

Rizzuto DS, Madsen JR, Bromfield EB, Schulze-Bonhage A, Kahana MJ. 2006. Human neocortical oscillations exhibit theta phase differences between encoding and retrieval. Neuroimage 31: 1352-1358.

Rosenbaum RS, Moscovitch M, Foster JK, Schnyer DM, Gao F, Kovacevic N, Verfaellie M, Black SE, Levine B. 2008. Patterns of autobiographical memory loss in medialtemporal lobe amnesic patients. J Cogn Neurosci 20: 1490-1506.

Rösler F, Heil M, Hennighausen E. 1995. Exploring memory functions by means of brain electrical topography: A review. Brain Topogr 7: 301-313.

Rossi S, Pasqualetti P, Zito G, Vecchio F, Cappa SF, Miniussi C, Babiloni C, Rossini PM. 2006. Prefrontal and parietal cortex in human episodic memory: An interference study by repetitive transcranial magnetic stimulation. Eur $J$ Neurosci 23: 793-800.

Rotello CM, Macmillan NA, Reeder JA. 2004. Sum-difference theory of remembering and knowing: A two-dimensional signal-detection model. Psychol Rev 111: 588.

Rudebeck SR, Scholz J, Millington R, Rohenkohl G, Johansen-Berg H, Lee AC. 2009. Fornix microstructure correlates with recollection but not familiarity memory. $\mathrm{J} \mathrm{Neu}$ rosci 29: 14987-14992.

Rugg MD, Vilberg KL. 2013. Brain networks underlying episodic memory retrieval. Curr Opin Neurobiol 23: 255-260.

Rugg MD, Wilding EL. 2000. Retrieval processing and episodic memory. Trends Cogn Sci 4: 108-115.

Rugg MD, Fletcher PC, Frith CD, Frackowiak RSJ, Dolan RJ. 1996. Differential activation of the prefrontal cortex in successful and unsuccessful memory retrieval. Brain 119: 2073-2083.

Rugg MD, Fletcher PC, Allan K, Frith CD, Frackowiak RSJ, Dolan RJ. 1998. Neural correlates of memory retrieval during recognition memory and cued recall. Neuroimage 8: $262-273$.

Rugg MD, Johnson JD, Park H, Uncapher MR. 2008. Encoding-retrieval overlap in human episodic memory: A functional neuroimaging perspective. Prog Brain Res 169: 339-352.

Rugg MD, Vilberg KL, Mattson JT, Yu SS, Johnson JD, Suzuki M. 2012. Item memory, context memory and the hippocampus: fMRI evidence. Neuropsychologia 50: 3070-3079.

Rutishauser U, Mamelak AN, Schuman EM. 2006. Singletrial learning of novel stimuli by individual neurons of 
A. Ben-Yakov et al.

the human hippocampus-amygdala complex. Neuron 49: 805-813.

Rutishauser U, Schuman EM, Mamelak AN. 2008. Activity of human hippocampal and amygdala neurons during retrieval of declarative memories. Proc Natl Acad Sci 105: 329-334.

Rutishauser U, Ross IB, Mamelak AN, Schuman EM. 2010. Human memory strength is predicted by theta-frequency phase-locking of single neurons. Nature 464: 903-907.

Sagar SM, Sharp FR, Curran T. 1988. Expression of c-fos protein in brain: Metabolic mapping at the cellular level. Science 240: 1328-1331.

Schacter DL, Addis DR. 2007. The cognitive neuroscience of constructive memory: Remembering the past and imagining the future. Philos Trans R Soc Lond B Biol Sci 362: 773-786.

Schacter DL, Slotnick SD. 2004. The cognitive neuroscience of memory distortion. Neuron 44: 149-160.

Schacter DL, Wagner AD. 1999. Medial temporal lobe activations in fMRI and PET studies of episodic encoding and retrieval. Hippocampus 9: 7-24.

Schacter DL, Norman KA, Koutstaal W. 1998. The cognitive neuroscience of constructive memory. Annu Rev Psychol 49: $289-318$.

Schacter DL, Addis DR, Buckner RL. 2008. Episodic simulation of future events. Ann NY Acad Sci 1124: 39-60

Schacter DL, Addis DR, Hassabis D, Martin VC, Spreng RN, Szpunar KK. 2012. The future of memory: Remembering, imagining, and the brain. Neuron 76: 677-694.

Schoenenberger P, Gerosa D, Oertner TG. 2009. Temporal control of immediate early gene induction by light. PLoS ONE 4: e8185.

Scimeca JM, Badre D. 2012. Striatal contributions to declarative memory retrieval. Neuron 75: 380-392.

Semon R. 1904/1921. The mneme. G. Allen \& Unwin, London.

Shannon BJ, Buckner RL. 2004. Functional-anatomic correlates of memory retrieval that suggest nontraditional processing roles for multiple distinct regions within posterior parietal cortex. J Neurosci 24: 10084-10092.

Shimamura AP. 1995. Memory and frontal lobe function. Ann NY Acad Sci 15: 769.

Shimamura AP. 2010. Hierarchical relational binding in the medial temporal lobe: The strong get stronger. Hippocampus 20: 1206-1216.

Shimamura AP. 2011. Episodic retrieval and the cortical binding of relational activity. Cogn Affect Behav Neurosci 11: 277-291.

Shohamy D, Wagner AD. 2008. Integrating memories in the human brain: Hippocampal-midbrain encoding of overlapping events. Neuron 60: 378-389.

Simons JS, Spiers HJ. 2003. Prefrontal and medial temporal lobe interactions in long-term memory. Nat Rev Neurosci 4: 637-648.

Simons JS, Owen AM, Fletcher PC, Burgess PW. 2005. Anterior prefrontal cortex and the recollection of contextual information. Neuropsychologia 43: 1774-1783.

Simons JS, Peers PV, Hwang DY, Ally BA, Fletcher PC, Budson AE. 2008. Is the parietal lobe necessary for recollection in humans? Neuropsychologia 46: 1185-1191.
Skinner EI, Fernandes MA. 2007. Neural correlates of recollection and familiarity: A review of neuroimaging and patient data. Neuropsychologia 45: 2163-2179.

Slotnick SD, Schacter DL. 2004. A sensory signature that distinguishes true from false memories. Nat Neurosci 7: 664-672.

Smeyne RJ, Schilling K, Robertson L, Luk D, Oberdick J, Curran T, Morgan JI. 1992. fos-lacZ transgenic mice: Mapping sites of gene induction in the central $n$ nervous system. Neuron 8: 13-23.

Smith CN, Wixted JT, Squire LR. 2011. The hippocampus supports both recollection and familiarity when memories are strong. J Neurosci 31: 15693-15702.

Söderlund H, Moscovitch M, Kumar N, Mandic M, Levine B. 2012. As time goes by: Hippocampal connectivity changes with remoteness of autobiographical memory retrieval. Hippocampus 22: 670-679.

Song Z, Wixted JT, Hopkins RO, Squire LR. 2011. Impaired capacity for familiarity after hippocampal damage. Proc Natl Acad Sci 108: 9655-9660.

Spaniol J, Davidson PS, Kim AS, Han H, Moscovitch M, Grady CL. 2009. Event-related fMRI studies of episodic encoding and retrieval: Meta-analyses using activation likelihood estimation. Neuropsychologia 47: 1765-1779.

Spreng RN, Mar RA, Kim AS. 2009. The common neural basis of autobiographical memory, prospection, navigation, theory of mind, and the default mode: A quantitative meta-analysis. J Cogn Neurosci 21: 489-510.

Squire LR, Bayley PJ. 2007. The neuroscience of remote memory. Curr Opin Neurobiol 17: 185-196.

* Squire LR, Dede AJO. 2015. Conscious and unconscious memory systems. Cold Spring Harb Perspect Biol doi: 10.1101/cshperspect.a021667.

Squire LR, Clark RE, Knowlton BJ. 2001. Retrograde amnesia. Hippocampus 11: 50-55.

Squire LR, Wixted JT, Clark RE. 2007. Recognition memory and the medial temporal lobe: A new perspective. Nat Rev Neurosci 8: 872-883.

* Squire LR, Morris RG, Genzel L, Wixted JT. 2015. Memory consolidation. Cold Spring Harb Perspect Biol doi: 10. 1101/cshperspect.a021766.

Staresina BP, Henson RN, Kriegeskorte N, Alink A. 2012a. Episodic reinstatement in the medial temporal lobe. $J$ Neurosci 32: 18150-18156.

Staresina BP, Fell J, Do Lam AT, Axmacher N, Henson RN. 2012b. Memory signals are temporally dissociated in and across human hippocampus and perirhinal cortex. Nat Neurosci 15: 1167-1173.

Stark CE, Okado Y. 2003. Making memories without trying: Medial temporal lobe activity associated with incidental memory formation during recognition. J Neurosci 23: 6748-6753.

Stark CE, Bayley PJ, Squire LR. 2002. Recognition memory for single items and for associations is similarly impaired following damage to the hippocampal region. Learn Mem 9: 238-242.

St Jacques PL, Kragel PA, Rubin DC. 2011. Dynamic neural networks supporting memory retrieval. Neuroimage 57: $608-616$. 
Strange BA, Fletcher PC, Henson RNA, Friston KJ, Dolan RJ. 1999. Segregating the functions of human hippocampus. Proc Natl Acad Sci 96: 4034-4039.

Stuss DT, Alexander MP, Palumbo CL, Buckle L, Sayer L, Pogue J. 1994. Organizational strategies with unilateral or bilateral frontal lobe injury in word learning tasks. $\mathrm{Neu}$ ropsychology 8: 355 .

Summerfield JJ, Hassabis D, Maguire EA. 2009. Cortical midline involvement in autobiographical memory. $\mathrm{Neu}$ roimage 44: $1188-1200$.

Suthana N, Fried I. 2012. Percepts to recollections: Insights from single neuron recordings in the human brain. Trends Cogn Sci 16: 427-436.

Svoboda E, McKinnon MC, Levine B. 2006. The functional neuroanatomy of autobiographical memory: A metaanalysis. Neuropsychologia 44: 2189-2208.

Szpunar KK. 2010. Episodic future thought an emerging concept. Perspect Psychol Sci 5: 142-162.

Tanaka KZ, Pevzner A, Hamidi AB, Nakazawa Y, Graham J, Wiltgen BJ. 2014. Cortical representations are reinstated by the hippocampus during memory retrieval. Neuron 84: $347-354$.

Tendolkar I, Arnold J, Petersson KM, Weis S, BrockhausDumke A, van Eijndhoven P, Buitelaar J, Fernández G. 2008. Contributions of the medial temporal lobe to declarative memory retrieval: Manipulating the amount of contextual retrieval. Learn Mem 15: 611-617.

Thorpe S, Fine D, Marlot C. 1996. Speed of processing in the human visual system. Nature 381: 520-522.

Tsivilis D, Vann SD, Denby C, Roberts N, Mayes AR, Montaldi D, Aggleton JP. 2008. A disproportionate role for the fornix and mammillary bodies in recall versus recognition memory. Nat Neurosci 11: 834-842.

Tulving E. 1983. Elements of episodic memory. Oxford University Press, Oxford.

Tulving E. 1985. Memory and consciousness. Can Psychol 26: 1 .

Tulving E, Thomson DM. 1973. Encoding specificity and retrieval processes in episodic memory. Psychol Rev 80: 352.

Tulving E, Kapur S, Craik FI, Moscovitch M, Houle S. 1994. Hemispheric encoding/retrieval asymmetry in episodic memory: Positron emission tomography findings. Proc Natl Acad Sci 91: 2016-2020.

Vaidya CJ, Zhao M, Desmond JE, Gabrieli JD. 2002. Evidence for cortical encoding specificity in episodic memory: Memory-induced re-activation of picture processing areas. Neuropsychologia 40: 2136-2143.

van der Meij R, Kahana M, Maris E. 2012. Phase-amplitude coupling in human electrocorticography is spatially distributed and phase diverse. J Neurosci 32: 111-123.

Vann SD, Aggleton JP, Maguire EA. 2009a. What does the retrosplenial cortex do? Nat Rev Neurosci 10: 792-802.

Vann SD, Tsivilis D, Denby CE, Quamme JR, Yonelinas AP, Aggleton JP, Montaldi D, Mayes AR. 2009b. Impaired recollection but spared familiarity in patients with $\mathrm{ex}$ tended hippocampal system damage revealed by 3 convergent methods. Proc Natl Acad Sci 106: 5442-5447.

Vargha-Khadem F, Gadian DG, Watkins KE, Connelly A Van Paesschen W, Mishkin M. 1997. Differential effects of early hippocampal pathology on episodic and semantic memory. Science 277: 376-380.

Viard A, Lebreton K, Chételat G, Desgranges B, Landeau B, Young A, De La Sayette V, Eustache F, Piolino P. 2010. Patterns of hippocampal-neocortical interactions in the retrieval of episodic autobiographical memories across the entire life-span of aged adults. Hippocampus 20: $153-165$.

Viard A, Desgranges B, Eustache F, Piolino P. 2012. Factors affecting medial temporal lobe engagement for past and future episodic events: An ALE meta-analysis of neuroimaging studies. Brain Cogn 80: 111-125.

Vilberg KL, Rugg MD. 2007. Dissociation of the neural correlates of recognition memory according to familiarity, recollection, and amount of recollected information. Neuropsychologia 45: 2216-2225.

Vilberg KL, Rugg MD. 2008. Memory retrieval and the parietal cortex: A review of evidence from a dual-process perspective. Neuropsychologia 46: 1787-1799.

Vilberg KL, Rugg MD. 2012. The neural correlates of recollection: Transient versus sustained fMRI effects. J Neurosci 32: 15679-15687.

Viskontas IV, Knowlton BJ, Steinmetz PN, Fried I. 2006. Differences in mnemonic processing by neurons in the human hippocampus and parahippocampal regions. $J$ Cogn Neurosci 18: 1654-1662.

Viskontas IV, Carr VA, Engel SA, Knowlton BJ. 2009. The neural correlates of recollection: Hippocampal activation declines as episodic memory fades. Hippocampus 19: 265-272.

Voss JL, Paller KA. 2010. Bridging divergent neural models of recognition memory: Introduction to the special issue and commentary on key issues. Hippocampus 20: 11711177.

Wagner AD, Desmond JE, Glover GH, Gabrieli JD. 1998. Prefrontal cortex and recognition memory. FunctionalMRI evidence for context-dependent retrieval processes. Brain 121: 1985-2002.

Wagner AD, Maril A, Bjork RA, Schacter DL. 2001. Prefrontal contributions to executive control: fMRI evidence for functional distinctions within lateral prefrontal cortex. Neuroimage 14: 1337-1347.

Wagner AD, Shannon BJ, Kahn I, Buckner RL. 2005. Parietal lobe contributions to episodic memory retrieval. Trends Cogn Sci 9: 445-453.

Wais PE. 2008. fMRI signals associated with memory strength in the medial temporal lobes: A meta-analysis. Neuropsychologia 46: 3185-3196.

Wais P, Wixted J, Hopkins R, Squire L. 2006. The hippocampus supports both the recollection and the familiarity components of recognition memory. Neuron 49: 459466.

Wais PE, Mickes L, Wixted JT. 2008. Remember/know judgments probe degrees of recollection. J Cogn Neurosci 20: 400-405.

Wais PE, Squire LR, Wixted JT. 2010. In search of recollection and familiarity signals in the hippocampus. $J \operatorname{Cog} n$ Neurosci 22: 109-123.

Watrous AJ, Tandon N, Conner CR, Pieters T, Ekstrom AD. 2013. Frequency-specific network connectivity increases 
A. Ben-Yakov et al.

underlie accurate spatiotemporal memory retrieval. Nat Neurosci 16: 349-356.

Watrous AJ, Fell J, Ekstrom AD, Axmacher N. 2015. More than spikes: Common oscillatory mechanisms for content specific neural representations during perception and memory. Curr Opin Neurobiol 31: 33-39.

Weiler JA, Suchan B, Daum I. 2010. When the future becomes the past: Differences in brain activation patterns for episodic memory and episodic future thinking. Behav Brain Res 212: 196-203.

Weis S, Specht K, Klaver P, Tendolkar I, Willmes K, Ruhlmann J, Elger CE, Fernández G. 2004. Process dissociation between contextual retrieval and item recognition. Neuroreport 15: 2729-2733.

Wheeler ME, Buckner RL. 2004. Functional-anatomic correlates of remembering and knowing. Neuroimage 21: 1337-1349.

Wheeler MA, Stuss DT, Tulving E. 1995. Frontal lobe damage produces episodic memory impairment. J Int Neuropsychol Soc 1: 525-536.

Wheeler ME, Petersen SE, Buckner RL. 2000. Memory's echo: Vivid remembering reactivates sensory-specific cortex. Proc Natl Acad Sci 97: 11125-11129.

Wheeler ME, Shulman GL, Buckner RL, Miezin FM, Velanova K, Petersen SE. 2006. Evidence for separate perceptual reactivation and search processes during remembering. Cereb Cortex 16: 949-959.

Wilson MA, McNaughton BL. 1994. Reactivation of hippocampal ensemble memories during sleep. Science 265: 676-679.

Wiltgen BJ, Silva AJ. 2007. Memory for context becomes less specific with time. Learn Mem 14: 313-317.

Winocur G, Moscovitch M, Bontempi B. 2010. Memory formation and long-term retention in humans and in animals: Convergence towards a transformation account of hippocampal-neocortical interactions. Neuropsychologia 48: 2339-2356

Wixted JT. 2004. The psychology and neuroscience of forgetting. Annu Rev Psychol 55: 235-269.

Wixted JT. 2007. Dual-process theory and signal-detection theory of recognition memory. Psychol Rev 114: 152.
Wixted JT, Mickes L. 2010. A continuous dual-process model of remember/know judgments. Psychol Rev 117: 1025.

Wixted JT, Squire LR. 2011. The medial temporal lobe and the attributes of memory. Trends Cogn Sci 15: 210-217.

Wixted JT, Mickes L, Squire LR. 2010. Measuring recollection and familiarity in the medial temporal lobe. Hippocampus 20: 1195-1205.

Woodruff CC, Johnson JD, Uncapher MR, Rugg MD. 2005. Content-specificity of the neural correlates of recollection. Neuropsychologia 43: 1022-1032.

Yonelinas AP. 1994. Receiver-operating characteristics in recognition memory: Evidence for a dual-process model. J Exp Psychol Learn Mem Cogn 20: 1341.

Yonelinas AP. 2002. The nature of recollection and familiarity: A review of 30 years of research. J Mem Lang 46: $441-$ 517.

Yonelinas AP, Jacoby LL. 2012. The process-dissociation approach two decades later: Convergence, boundary conditions, and new directions. Mem Cognit 40: 663-680.

Yonelinas AP, Kroll NE, Quamme JR, Lazzara MM, Sauvé MJ, Widaman KF, Knight RT. 2002. Effects of extensive temporal lobe damage or mild hypoxia on recollection and familiarity. Nat Neurosci 5: 1236-1241.

Yonelinas AP, Otten LJ, Shaw KN, Rugg MD. 2005. Separating the brain regions involved in recollection and familiarity in recognition memory. J Neurosci 25: 3002-3008.

Yonelinas AP, Aly M, Wang WC, Koen JD. 2010. Recollection and familiarity: Examining controversial assumptions and new directions. Hippocampus 20: 1178-1194.

Yu SS, Johnson JD, Rugg MD. 2012. Hippocampal activity during recognition memory co-varies with the accuracy and confidence of source memory judgments. Hippocampus 22: 1429-1437.

Zeineh MM, Engel SA, Thompson PM, Bookheimer SY. 2003. Dynamics of the hippocampus during encoding and retrieval of face-name pairs. Science 299: 577-580.

Ziv Y, Burns LD, Cocker ED, Hamel EO, Ghosh KK, Kitch LJ, El Gamal A, Schnitzer MJ. 2013. Long-term dynamics of CA1 hippocampal place codes. Nat Neurosci 16: $264-$ 266. 


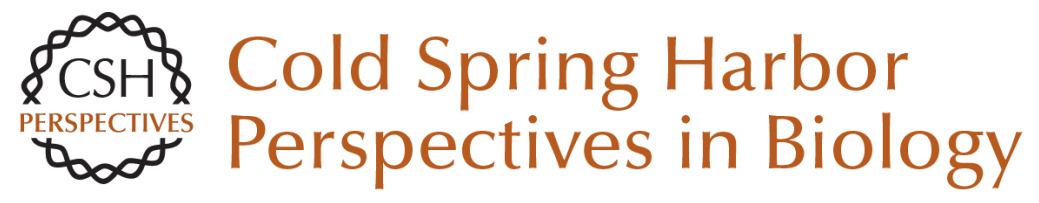

\section{Memory Retrieval in Mice and Men}

Aya Ben-Yakov, Yadin Dudai and Mark R. Mayford

Cold Spring Harb Perspect Biol 2015; doi: 10.1101/cshperspect.a021790 originally published online October 5, 2015

\section{Subject Collection Learning and Memory}

Large-Scale Fluorescence Calcium-Imaging Methods for Studies of Long-Term Memory in Behaving Mammals Pablo Jercog, Thomas Rogerson and Mark J. Schnitzer

Exploring Memory Representations with

Activity-Based Genetics

Mark Mayford and Leon Reijmers

The Origins and Organization of Vertebrate

Pavlovian Conditioning

Michael S. Fanselow and Kate M. Wassum

The Corticohippocampal Circuit, Synaptic

Plasticity, and Memory Jayeeta Basu and Steven A. Siegelbaum

Motor Learning and the Cerebellum Chris I. De Zeeuw and Michiel M. Ten Brinke

The Striatum: Where Skills and Habits Meet Ann M. Graybiel and Scott T. Grafton

Molecular Genetic Strategies in the Study of Corticohippocampal Circuits

Christopher C. Angelakos and Ted Abel

Nonassociative Learning in Invertebrates John H. Byrne and Robert D. Hawkins
The Role of Functional Prion-Like Proteins in the Persistence of Memory

Kausik Si and Eric R. Kandel

Working Memory: Maintenance, Updating, and the

Realization of Intentions

Lars Nyberg and Johan Eriksson

Memory Retrieval in Mice and Men Aya Ben-Yakov, Yadin Dudai and Mark R. Mayford

Reconsolidation and the Dynamic Nature of

Memory

Karim Nader

Memory Consolidation

Larry R. Squire, Lisa Genzel, John T. Wixted, et al.

Structural Components of Synaptic Plasticity and Memory Consolidation

Craig H. Bailey, Eric R. Kandel and Kristen M. Harris

Associative Learning in Invertebrates Robert D. Hawkins and John H. Byrne

The Regulation of Transcription in Memory Consolidation Cristina M. Alberini and Eric R. Kandel

For additional articles in this collection, see http://cshperspectives.cshlp.org/cgi/collection/

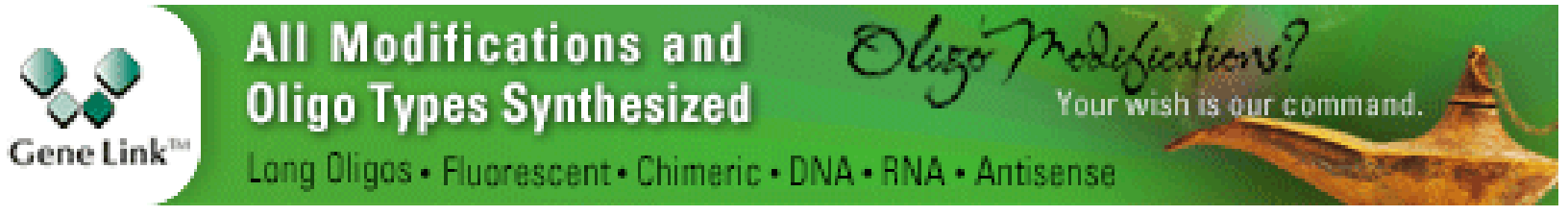

